\title{
Lost in Transmission? \\ The Effectiveness of Monetary Policy \\ Transmission Channels in the GCC Countries
}

Serhan Cevik and Katerina Teksoz 


\title{
IMF Working Paper
}

Middle East and Central Asia Department

\section{Lost in Transmission? \\ The Effectiveness of Monetary Policy Transmission Channels in the GCC Countries Prepared by Serhan Cevik and Katerina Teksoz*}

Authorized for distribution by Ralph Chami

July 2012

\section{This Working Paper should not be reported as representing the views of the IMF.} The views expressed in this Working Paper are those of the author(s) and do not necessarily represent those of the IMF or IMF policy. Working Papers describe research in progress by the author(s) and are published to elicit comments and to further debate.

\begin{abstract}
This paper empirically investigates the effectiveness of monetary policy transmission in the Gulf Cooperation Council (GCC) countries using a structural vector autoregressive model. The results indicate that the interest rate and bank lending channels are relatively effective in influencing non-hydrocarbon output and consumer prices, while the exchange rate channel does not appear to play an important role as a monetary transmission mechanism because of the pegged exchange rate regimes. The empirical analysis suggests that policy measures and structural reforms - strengthening financial intermediation and facilitating the development of liquid domestic capital markets - would advance the effectiveness of monetary transmission mechanisms in the GCC countries.
\end{abstract}

JEL Classification Numbers: C51, E4, E5, E31, E50, E51, E52, O53

Keywords: Monetary policy transmission, inflation, credit channel, structural VAR

Authors’ E-Mail Addresses: scevik@imf.org; kk2900@,columbia.edu

\footnotetext{
* The authors would like to thank Ahmed Al-Darwish, Elif Arbatli, Joshua Charap, Selim Elekdag, Davide Furceri, Felix Hammermann, Prachi Mishra, Kia Penso, Ananthakrishnan Prasad, Mohammad Rahmati, Gabriel Sensenbrenner, Jan Strasky, Michael Sturm, Anke Weber, and participants of the MCD Discussion Forum for their insightful comments and suggestions. Arthur Ribeiro da Silva and Renas Sidahmed provided excellent research assistance.
} 
Contents

Page

Abstract 1

I. Introduction 3

II. An Overview of The Channels of Monetary Policy Transmission ....................................5

III. A Brief Overview of Economic Developments ................................................................

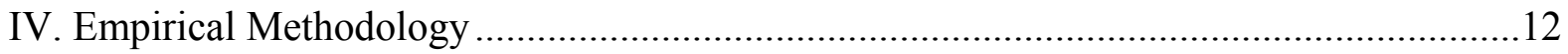

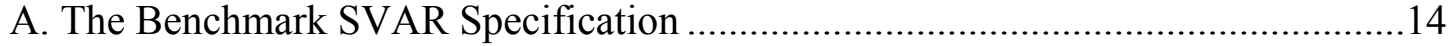

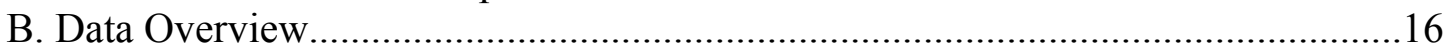

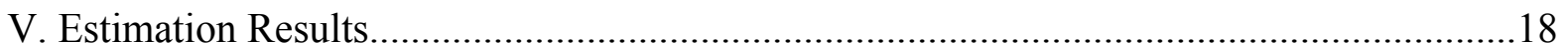

VI. Analyzing the Robustness of the Results................................................................20

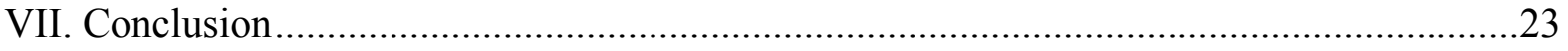

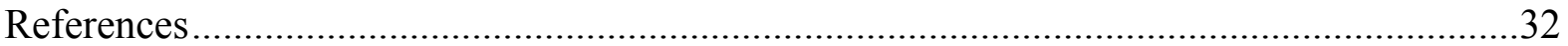

Tables

1. Unit Root Tests Results for GCC Countries .............................................................. 17

2. Specification tests of the GCC SVAR ...................................................................... 18

3. Estimated Contemporaneous SVAR Coefficients, 1900-2010 …................................20

4. GCC: Variance Decomposition (Percent of Total Variance) …........................................22

Figures

1. GCC: Real Non-hydrocarbon GDP Growth and Inflation, 1991-2010........................10

2. GCC and U.S. Nominal Short-Term Interest Rates, 2004-2010 ................................11

Appendix Figures

1. GCC: Impulse Responses with Bootstrapped Confidence Intervals..............................25

2. Bahrain: Impulse Responses with Bootstrapped Confidence Intervals ...........................25

3. Kuwait: Impulse Responses with Bootstrapped Confidence Intervals ............................26

4. Oman: Impulse Responses with Bootstrapped Confidence Intervals ..............................26

5. Qatar: Impulse Responses with Bootstrapped Confidence Intervals ...............................27

6. Saudi Arabia: Impulse Responses with Bootstrapped Confidence Intervals....................27

7. U.A.E.: Impulse Responses with Bootstrapped Confidence Intervals............................28

8. GCC: Variance Decomposition with Bootstrapped Confidence Intervals ......................28

9. Bahrain: Variance Decomposition with Bootstrapped Confidence Intervals ...................29

10. Kuwait: Variance Decomposition with Bootstrapped Confidence Intervals ....................29

11. Oman: Variance Decomposition with Bootstrapped Confidence Intervals ......................30

12. Qatar: Variance Decomposition with Bootstrapped Confidence Intervals .......................30

13. Saudi Arabia: Variance Decomposition with Bootstrapped Confidence Intervals.............31

14. U.A.E.: Variance Decomposition with Bootstrapped Confidence Intervals .....................31 


\section{INTRODUCTION}

Empirically evaluating the efficacy of monetary transmission channels provides central banks with pertinent insight for better decision-making. Monetary transmission - the process through which monetary policy action is transmitted into the economy-remains a central matter of debate in macroeconomics. Unless policymakers know more about how monetary policy decisions influence macroeconomic variables such as aggregate output, employment, and consumer prices through the different channels of monetary transmission, they will always be facing greater uncertainty about the timing and effectiveness of policy actions and consequently in maintaining macro-financial stability. Accordingly, gathering evidence on the efficacy of monetary policy transmission remains a priority, especially in the aftermath of the global financial crisis, which has disrupted some channels of monetary transmission.

\section{The primary objective of monetary policy in the Gulf Cooperation Council (GCC)} countries is to maintain the pegged exchange rate regime. ${ }^{1}$ With exchange rates pegged to the U.S. dollar, the GCC central banks have limited scope for discretionary monetary policy; consequently the primary responsibility for macroeconomic stabilization and demand management falls on fiscal institutions and, to lesser extent, macroprudential regulatory measures. Nevertheless, even within the limits of a fixed exchange rate regime, the channels of monetary transmission can play an important role. Accordingly, identifying and assessing the significance of different transmission mechanisms is still necessary for the successful design and conduct of monetary policy. Furthermore, since its establishment in 1981 as a regional cooperation platform, the GCC has moved toward closer economic and financial integration, aiming to form a monetary union. This objective alone requires a better understanding of the monetary transmission process and requires the development of instruments that can reinforce the efficacy of monetary policy transmission. ${ }^{2}$

We assess the effectiveness of monetary transmission mechanisms in the GCC by using structural vector autoregressive (SVAR) models. The functioning of monetary transmission channels varies across countries due to differences in the extent of financial intermediation, the level of development of domestic capital markets, the degree of central bank autonomy, and each country's specific structural economic conditions. While there is ample theoretical and empirical literature on how monetary shocks affect macroeconomic aggregates in developed and emerging economies with well-functioning financial markets,

\footnotetext{
${ }^{1}$ The GCC is comprised of six countries along the Arabian Gulf-Kuwait, Bahrain, Oman, Qatar, Saudi Arabia, and the United Arab Emirates - that have pegged their exchange rates to the U.S. dollar for more than three decades, except Kuwait with a peg to an undisclosed basket of currencies.

${ }^{2}$ Although the GCC countries remain committed to monetary integration, Oman and the United Arab Emirates have opted out at this stage and the launch of the single currency has been postponed for an unspecified period.
} 
little is known about the empirics of monetary policy transmission in the GCC countries. Therefore, the purpose of this paper is to provide an empirical analysis of the effect of various conventional channels of monetary policy transmission on aggregate demand, and to discern pertinent insights for the conduct of monetary policy. From a methodological standpoint, there are various approaches that involve certain assumptions of how monetary transmission works, especially under a fixed exchange rate regime, depending on the importance they place on money supply, bank lending, interest rates, exchange rates, or asset prices. Accordingly, we estimate a SVAR model for the period 1990-2010, with quarterly data for individual countries and separately a "synthetic" aggregate for the GCC as a whole, to identify the empirical patterns and relative importance of different channels of monetary transmission. ${ }^{3}$

\section{The interest rate and bank lending channels appear to be effective in transmission, while exchange rates do not play an important role. Using a standard identification} scheme and imposing minimal empirically-binding theoretical constraints on how monetary policy actions affect the real economy, we uncover plausible impulse response functions to structural shocks. The results presented in this paper indicate that the interest rate channel has a significant influence on real non-hydrocarbon output and the consumer price index (CPI), while the exchange rate channel does not appear to have a meaningful role in monetary transmission. These findings are consistent with the results of a recent study of the GCC countries by Espinoza and Prasad (2012) and the empirical evidence found in other countries, such as Denmark and Hong Kong, operating under a fixed exchange rate regime. ${ }^{4}$ Our analysis also shows a dominant role performed by the bank lending channel in transmitting monetary shocks, in line with the findings of Ziaei (2009) that highlight the significance of the credit channel in ten countries in the Middle East and North Africa. We find that bank lending tends to increase with monetary expansion and that the impact of monetary policy shocks typically depends on the propagation mechanism. Furthermore, our results complement earlier studies on other emerging markets suggest that the effectiveness of interest rate and bank lending channels depends largely on the bank balance sheets. ${ }^{5}$

The remainder of this paper is structured as follows. Section II provides a brief overview of the various conventional channels of monetary transmission, followed in Section III by an

\footnotetext{
${ }^{3}$ Sims (2012) provides a concise assessment of the evolution of statistical modeling of how monetary policy affects economic activity.

${ }^{4}$ In Denmark, the relative importance of traditional transmission mechanisms, such as the credit channel, declined before the introduction of the euro peg, while the bank lending channel in Hong-Kong has had a more significant impact on economic activity, particularly through the housing market.

${ }^{5}$ Bank consolidation in the case of Latin American and Asian countries, or securitization in the case of European countries, can weaken the credit channel of monetary transmission by reducing the sensitivity to monetary policy shocks (Altunbas, Gambacorta, and Marqués-Ibáñez, 2007; Olivero, Li, and Jeon, 2011).
} 
analysis of recent macroeconomic developments and the financial infrastructure in the GCC countries that underpin the monetary transmission process. Section IV describes the empirical methodology and the benchmark SVAR specification. In Section V, we present an empirical assessment of monetary policy transmission mechanisms for individual GCC countries and for a "synthetic" GCC aggregate, while Section VI provides robustness checks and an analysis of impulse response functions and variance decomposition over time. In Section VII, we offer concluding remarks focusing on structural constraints on monetary transmission on areas where reforms would enhance the effectiveness of monetary policy actions in the GCC countries.

\section{An Overview of The Channels of Monetary Policy Transmission}

\section{The structural features of the economy and financial markets influence the effectiveness} of various channels of monetary policy transmission. Monetary policy works mostly through its influence on aggregate demand, with somewhat limited direct impact on the supply side depending on the degree of interest rate pass-through and the extent of price rigidities. ${ }^{6}$ There are several channels of monetary policy transmission, but the functioning and effectiveness of these mechanisms vary across countries due to differences in the extent of financial intermediation, the development of domestic capital markets, and structural economic conditions.

- $\quad$ The interest rate channel operates through the impact of monetary shocks on liquidity conditions and real interest rates, which in turn affect interest rate sensitive components of aggregate demand such as consumption and investment. Although the interest rate channel is the long-established mechanism of monetary transmission, it may not account for the full extent of output fluctuations, particularly in a small open economy (Taylor, 1995; and Mishkin, 1996).

- $\quad$ The bank lending (or credit) channel works through the response of credit aggregates to changes in interest rates and other policy instruments. Therefore, the credit channel is an extension - an enhancement mechanism - to the interest rate channel and amplifies the real effects of monetary policy through changes in the supply of bank credit (Bernanke and Blinder, 1992; and Bernanke and Gertler, 1995). The necessary condition for the credit channel to operate is the significant role of banks as a source of capital for the private sector, especially in bank-based emerging market economies.

\footnotetext{
${ }^{6}$ The concept of long-run monetary neutrality argues that an increase in money supply affects only nominal variables such as the price level in the short run and would be offset by an equal rise of prices and wages. However, as Blanchard (1990) argues, long-run neutrality of money is rather a matter of faith, based more on theoretical considerations than on empirical evidence. For example, supply-side effects (e.g., more flexible labor markets) may imply that negative supply shocks are absorbed with a smaller increase in inflationary pressures, given the limited extent of second-round effects.
} 
- $\quad$ The exchange rate channel works through the impact of monetary developments on exchange rates and aggregate demand and supply. For example, an increase in interest rates would normally lead to an appreciation of the exchange rate, which lowers the price of imported goods and services and thereby pushes down domestic inflation. ${ }^{7}$ The effectiveness of the exchange rate channel depends on the exchange rate regime, the extent of exchange rate pass-through and the degree of openness to capital flows (Taylor, 1995). In a small open economy with a flexible exchange rate regime, the exchange rate channel is typically an important transmission mechanism for monetary policy actions. Alternatively, when the exchange rate is fixed, as it is the case in the GCC countries, domestic interest rates track foreign interest rates, leaving little or no room for domestic monetary policy.

- The balance sheet channel operates through the impact of monetary innovations on the net wealth and credit worthiness of households and companies. In other words, like the bank lending channel, wealth effects influences consumption demand through changes in real money balances of households and firms that rely on borrowed funds (Mishkin, 1996).

- $\quad$ The asset price channel operates through the impact of monetary shocks on yields, equity shares, real estate, and other domestic assets, operating through changes in the market value of corporate and household wealth. Changes in short-term interest rates and/or other policy instruments can alter firms' capacity for fixed investment spending through balance sheet effects, and household consumption through wealth effects (Mishkin, 1995).

- $\quad$ The expectations channel works through the impact of monetary shocks on the perception of households and firms about intertemporal rates of substitution. Inflation expectations, for example, play a pivotal role by influencing interest rates, exchange rate movements, wages, aggregate demand, and domestic prices (Taylor, 1995).

\section{The effectiveness of monetary transmission mechanisms vary and evolve over time, depending on structural economic and financial conditions. Although monetary} transmission channels have distinctive effects on the real economy, there are also possible interlinkages between the channels through which they may magnify or counteract the influence of other channels in the monetary transmission process. Depending on the structure of the economy and financial markets, the effectiveness of various monetary transmission mechanisms varies and evolves over time. Empirical evidence has shown that the interest rate

\footnotetext{
${ }^{7}$ Under a flexible exchange rate regime, currency depreciation is likely to lead to an increase in import prices, albeit imported inflation could be less of a problem than it is in countries with pegged exchange rate regimes. For example, inflationary pressures increased in the GCC countries, before the recent global financial crisis, as import prices surged with higher food prices and the declining value of the U. S. dollar.
} 
channel is usually the most important transmission mechanism in advanced economies with developed financial markets, while the bank lending and exchange rate channels are generally the dominant channels of monetary transmission in emerging market economies. The exchange rate channel, on the other hand, appears to be more important in small open economies with flexible exchange rates, where the transmission mechanism of the interest rate channel is relatively weak.

\section{A BRIEF OVERVIEW OF ECONOMIC DEVELOPMENTS}

The GCC economies performed well during the 2003-08 oil boom, but the growth surge also led to macro-financial imbalances. The Gulf region as a whole experienced a surge in real GDP growth to an average of 6.6 percent a year during the 2003-08 oil boomthree percentage points above the pre-boom period (1997-2002). Furthermore, real nonhydrocarbon GDP growth - a more appropriate measure of employment-creating economic activity in hydrocarbon-based countries - averaged 7.3 percent a year during the same period, compared to 4.8 percent during 1997-2002 (Figure 1). The large increase in hydrocarbon revenues resulted in fiscal surpluses averaging 26 percent of GDP in 2008, compared with minimal surpluses, or even deficits, in the pre-boom years. Nevertheless, measured by the non-hydrocarbon primary balance, the average GCC-wide fiscal position deteriorated by 10 percentage points from its average in the pre-boom years to a deficit of 51 percent of non-hydrocarbon GDP in 2008.

\section{Significant increases in bank credit to the private sector contributed to the rise of non- hydrocarbon sectors in the GCC countries. Average real credit growth was close to} 23 percent a year during 2003-08, almost doubling the ratio of private-sector credit to nonhydrocarbon GDP to 122 percent by end-2008. ${ }^{8}$ The cumulative deviation from trend credit/non-hydrocarbon GDP — a simple measure of excess credit — was significant in all countries, ranging between 35 percent of non- hydrocarbon GDP in Bahrain to 70 percent in the United Arab Emirates, and contributed to higher domestic demand. Accordingly, average inflation in the GCC countries increased from 1.7 percent in 2004 to 10.7 percent in 2008. As the economic cycles in the GCC and the United States diverged significantly in 2007 and the first half of 2008, policy action was limited by the pegged exchange rate regime. Inflationary pressures, combined with appreciations of the real effective exchange rates given large terms of trade gains, triggered capital inflows into the region, further exacerbating these pressures. ${ }^{9}$

\footnotetext{
${ }^{8}$ Non-hydrocarbon GDP is the more relevant measure of credit expansion because the hydrocarbon sector has required a negligible amount of domestic financing in recent years of high oil prices.

${ }^{9}$ The impact of rising consumer price inflation on the real effective exchange rate of Gulf currencies during this period was largely offset by the depreciation of the nominal effective exchange rate of the U.S. dollar, which resulted in a depreciation of the GCC currencies against their trading partners' currencies, mainly in Asia.
} 


\section{The global economic and financial crisis hit the GCC economies through trade and} financial channels. Real growth in the GCC's non-hydrocarbon sector declined by about half in 2009, albeit surpassing growth in advanced economies by a large margin and outperforming other emerging markets. The decline in global oil demand had a significant impact on hydrocarbon GDP and, combined with lower oil prices, led to weaker fiscal and external balances. At the same time, the GCC countries underwent reversals of the speculative capital inflows that were experienced in 2007 and early 2008. These developments tightened liquidity conditions and affected investor confidence, and were further exacerbated by the ensuing global liquidity shortages and deleveraging. Tighter liquidity conditions and the subsequent slowdown in economic activity led to the bursting of real estate price bubbles in most GCC countries. As a result, coupled with the fall in import prices, slowing domestic aggregate demand - with its particular impact on rents - caused annual inflation to decline from double digits in 2008 to 3.3 percent in $2009 .{ }^{10}$

\section{Economic activity has rebounded across the GCC, albeit at varying rates and led} mainly by higher oil prices and production. Average real GDP growth recovered to about 5 percent in 2010, driven by the hydrocarbon sector as countries expanded production, and to varying degrees, by fiscal stimulus. Non-hydrocarbon GDP growth, however, stabilized below trend at 4.2 percent, despite unprecedented levels of public spending. While the rise in hydrocarbon revenues brought a marked improvement in fiscal and external balances, consumer price inflation increased to 3.2 percent, on average, in 2010, driven by higher import prices. On the whole, economic performance during and after the crisis exhibited considerable differences among the GCC economies, reflecting country-specific economic, financial and structural idiosyncrasies. For example, the share of non-hydrocarbon sectors is 75 percent of GDP in Bahrain and 66 percent in the United Arab Emirates, whereas others remain more dependent on the hydrocarbon complex. Nevertheless, the main channels of economic diversification - financialization and real estate investments - and varying degrees of openness have made them prone to sector-specific domestic and international shocks.

\section{Structural impediments appear to hinder the effectiveness of monetary transmission channels in the GCC countries. The structure of the banking system and the extent of domestic financial development have a significant bearing on the effectiveness of monetary transmission. Although the GCC countries experienced rapid financial deepening over the past decade, the banking systems remain relatively underdeveloped and dominated by the}

\footnotetext{
${ }^{10}$ To offset the fallout from the global financial crisis, the GCC governments maintained - or even increasedspending levels, despite a sharp fall in hydrocarbon revenues, and also introduced exceptional financial measures to support domestic banks. Tracking the monetary easing cycle in the United States, the GCC central banks lowered interest rates, and eased liquidity through direct injections into the money market and through statutory changes, including reductions in reserve requirements and relaxation of prudential loan-to-deposit ratios.
} 
public sector, which tend to inhibit the efficacy of monetary policy transmission channels. ${ }^{11}$ Similarly, when the exchange rate is the main objective of - and the anchor for - monetary policy, the central bank cannot pursue an independent and countercyclical policy; fiscal policy then becomes the most potent tool for demand management. As a result, with pegged exchange rate regimes, nominal short-term interest rates throughout the GCC countries have generally moved in tandem with the U.S. Federal Reserve's fund target rate, while showing occasional signs of divergence because of domestic factors and international capital flows (Figure 2). Furthermore, according to Espinoza and Prasad (2012), the U.S. monetary policy stance has a robust and statistically significant effect on macroeconomic developments across the GCC countries, while the degree of pass-through from domestic interbank rates to domestic deposit and lending rates is low in the cases of Bahrain, Kuwait, Oman, and Qatar. ${ }^{12}$ This is mainly a manifestation of structural impediments, such as underdeveloped domestic capital markets and banking systems dominated by government-sponsored institutions, which tend to diminish the responsiveness of financial intermediation to monetary policy.

\section{The GCC central banks use macro-prudential measures to regulate bank lending, but} their efficacy is debatable in an open economy. Under the pegged exchange rate regime, the GCC central banks closely follow the interest rate cycle in the United States, albeit with some degree of divergence, and rely on liquidity and reserve requirements in conducting monetary policy. ${ }^{13}$ Although macro-prudential regulatory measures to influence monetary conditions - and, thereby, aggregate domestic demand - are outside the traditional toolbox of central bankers, the authorities also utilize them through changes in money multiplier or changes in the cost of funding for the banking sector. Nevertheless, while the monetary transmission mechanism can be affected by the use of regulatory measures, their effectiveness is an open question in the context of an open economy without any strict restriction on capital movements.

\footnotetext{
${ }^{11}$ The issue of monetary policy transmission under Islamic banking is beyond the scope of this paper, but this fast-growing segment of banking sectors may behave differently, compared to conventional banks, in transmitting monetary policy shocks.

${ }^{12}$ Data for deposit and lending rates are not available for Saudi Arabia and the United Arab Emirates.

${ }^{13}$ Prasad and Khamis (2011) provide a comprehensive description of macro-prudential measures used by the GCC central banks.
} 
Figure 1. GCC: Real Non-hydrocarbon GDP Growth and Inflation, 1991 - 2010
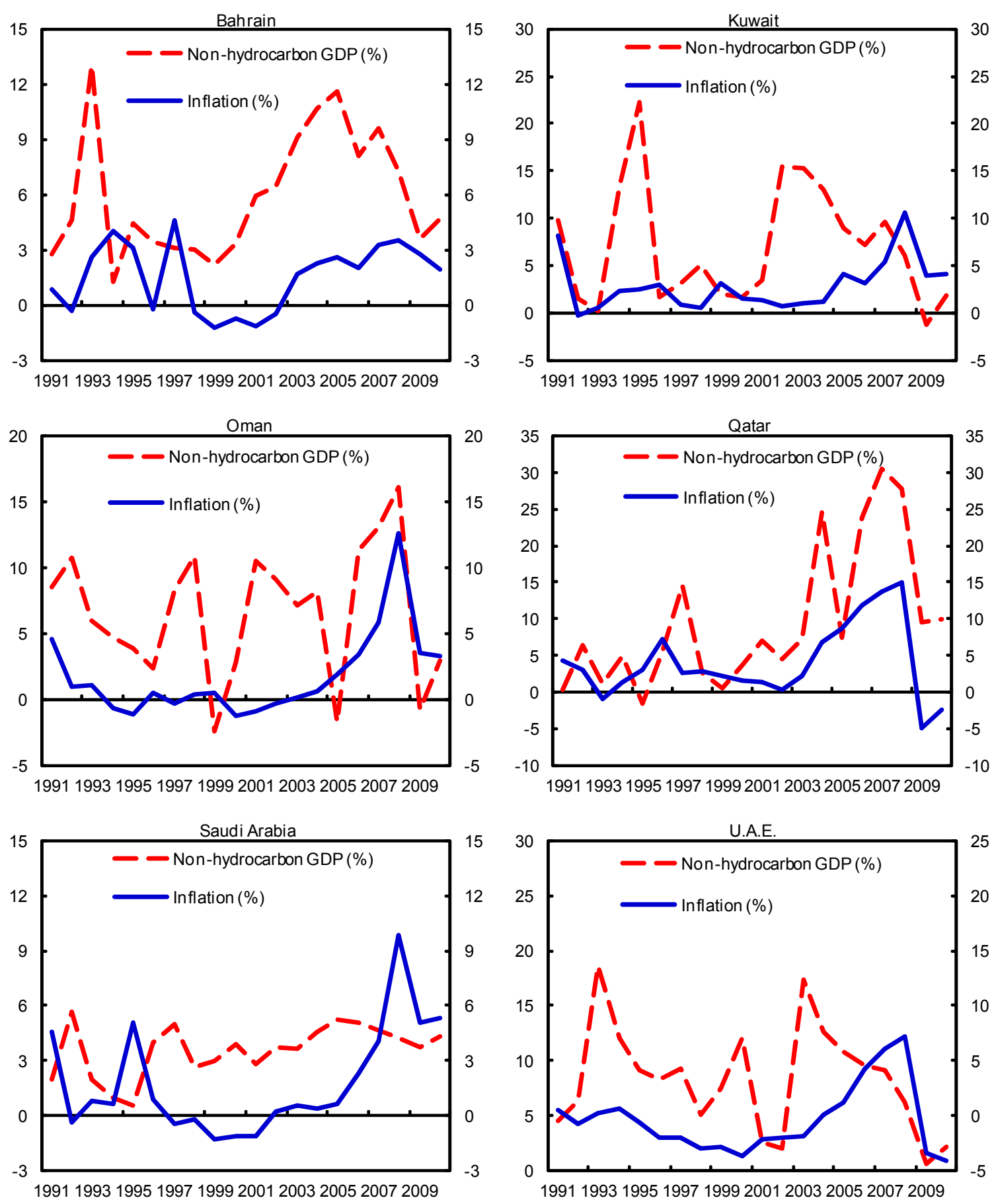

Source: Country authorities; and authors' calculations. 
Figure 2. Nominal Short-Term Interest Rates, 2004-2010
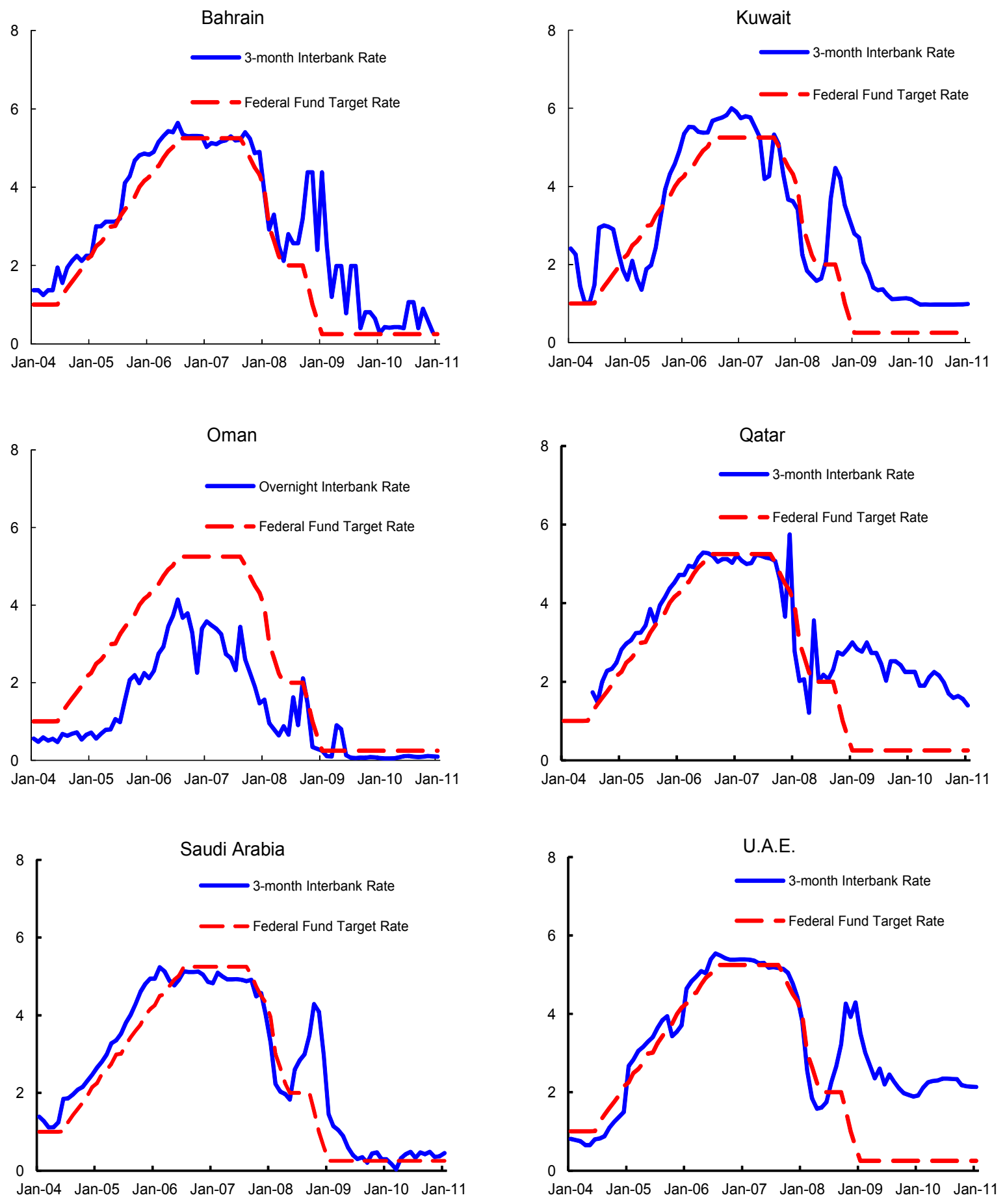

Source: Country authorities; U.S. Federal Reserve 


\section{EMPIRICAL METHODOLOGY}

The empirical analysis of the impact of monetary policy actions on economic activity is conducted using a SVAR framework. To determine the effects of monetary policy, we need to identify how macroeconomic variables respond to specific shocks and ascertain whether the propagation of monetary policy shocks evolves over time. ${ }^{14}$ The VAR approach pioneered by Sims (1980) provides an ideal instrument for forecasting exercises as well as policy analysis, especially in view of the problems induced by data constraints and structural changes. In a seminal paper, Blanchard and Quah (1989) utilized the VAR approach to analyze the source of business cycle fluctuations in the United States and illustrated the role of orthogonality restriction for the structural shocks using a bivariate model for the unemployment rate and the output growth where a demand shock cannot have long-run effects on the level of output. Along the same lines, there is a bourgeoning empirical literature using different VAR methods to investigate the impact of monetary policy actions on macroeconomic variables in advanced and developing countries. ${ }^{15}$

The SVAR approach allows for contemporaneous feedback between variables, while imposing the minimal structural restrictions. An analysis of long-run, short-run, and contemporaneous relationships between monetary aggregates and key macroeconomic variables requires restrictions on the correlation structure of the residuals. In other words, identification focuses on the errors of the system that are interpreted as linear combinations of exogenous shocks presenting the effect of a unit shock of one variable on another variable. Different approaches can be taken to this task. One approach is the Cholesky decomposition together with the assumption that the contemporaneous relationships between the variables have a recursive structure, which results in a temporal ordering of the variables. Another approach uses the information given by the history of the variables through impulse response functions. A third possibility is to adopt restrictions according to the economic theory to identify the structural components of the error terms.

\footnotetext{
The SVAR framework helps model the relations between deviations of the variables from the respective expected values. The aim is to obtain the structural (orthogonal) components of the error term and to evaluate the implied impulse response functions of different models. For the validity of this approach, the variables need to be stationary. Contemporaneous interactions considered in the SVAR model occur between deviations from expectations in the theoretical model and residuals in the empirical model, as outlined

${ }^{14}$ We test whether the volatility of real non-hydrocarbon output, consumer price inflation, short-term interest rates and real effective exchange rates is due to smaller/larger disturbances (the size of shock) and more/less frequent disturbances (the propagation of shock) to productivity, external demand, and changes in fiscal and monetary policy variables.

${ }^{15}$ Christiano, Eichenbaum, and Evans (1999) provide a detailed survey on the use of SVAR models in estimating the effectiveness of monetary policy transmission.
} 
by Bernanke and Mihov (1998) in identifying monetary policy shocks in the case of the U.S. economy. Notwithstanding its many advantages, the SVAR framework is also subject to limitations. A widely recognized problem is that the estimation results are sensitive to the identifying assumptions; this sensitivity can lead to substantial variations in the estimated effects of monetary policy shocks and in their relative importance over the sample period. A popular restriction, used to identify monetary policy shocks, is that monetary policy has no instantaneous impact on output and inflation. While the assumption is appealing given the broadly held view that the effects of monetary policy take a considerable time to be felt, its use has been associated with a number of puzzles. For example, the price puzzle is the tendency of prices to increase temporarily after surprise interest rate hikes (Sims, 1992), while the exchange rate puzzle is the tendency of exchange rates to depreciate temporarily after a contractionary monetary policy shock (Grilli and Roubini, 1993).

The orthogonality assumption of the underlying shocks is somewhat restrictive because of the low dimension of many SVAR models. ${ }^{16}$ There are various approaches used in the VAR literature to identify orthogonal disturbances, but the most common methodology is the Cholesky decomposition, which assigns all correlations between orthogonal errors to the equation that is earliest in the ordering. The Cholesky decomposition presumes that a shock to a variable does not contemporaneously affect the variables that precede it in the ordering, but does affect them with a lag. Accordingly, given the sensitivity of the Cholesky approach to the ordering of variables, we use a model-based identification strategy to estimate the impact of the shocks. The restrictions applied in the SVAR to identify a monetary shock are that a contractionary shock increases interest rates, appreciates the exchange rate, and reduces output, inflation and the money supply. Clarida and Gali (1994) use a long-run restriction - that a nominal shock would not affect the real exchange rate as an identifying strategy - in a three variable VAR, where all the variables are measured in differences so that all shocks are permanent. In this paper, we construct the confidence intervals by using the standard errors and the bootstrap procedure with higher accuracy as in Kilian (1998), through which the residuals are being resampled and a new equation is fit with the resampled residuals. ${ }^{17}$ The equation with the coefficients obtained by bootstrapping is used to determine the confidence intervals for impulse response functions from the SVAR model. Since shortrun or long-run identifying restrictions can be specified within pattern matrices, we employ a

\footnotetext{
${ }^{16}$ For example, Blanchard and Quah (1989) estimate the output response during specific business cycle episodes to identify aggregate demand shocks, but do not identify the output response to foreign demand shocks.

${ }^{17}$ Bootstrapping is a method for estimating confidence intervals when series differ from the asymptotic normal distribution; and it requires no knowledge of the actual distribution (e.g., it does not have to be normal).
} 
long-run identification scheme in terms of the $C$ matrix, where the response of a specific variable to a specific structural shock is zero over the long run. ${ }^{18}$

\section{A. The Benchmark SVAR Specification}

The benchmark SVAR model that we use to analyze the effects of a monetary policy shock in the GCC countries has the following representation:

$$
Y_{t}=C_{t}+\sum_{k=1}^{n} A_{t} Y_{t-k}+\sum_{k=1}^{n} B_{t} X_{t-k}+u_{t}
$$

where $C_{t}$ is a vector of constant terms, $Y_{t}$ is the vector of endogenous variables, and $X_{t}$ is a vector of exogenous variables. ${ }^{19} A_{t}$ and $B_{t}$ represent a matrix of coefficients, while $u_{t}$ is a vector of innovations. Throughout this paper, the vector of exogenous variables contains the price of crude oil measured by the quarterly average of Brent and West Texas Intermediate $\left(o p_{t}\right)$, U.S. real GDP $\left(y_{t}^{U S}\right)$, and the U.S. nominal short-term interest rate $\left(s_{t}^{U S}\right)$ :

$$
X_{t}^{\prime}=\left[\begin{array}{lll}
\operatorname{op}_{t} & y_{t}^{U S} & S_{t}^{U S}
\end{array}\right]
$$

These exogenous variables are included in the empirical model to control for the changes in economic conditions in the United States and worldwide. Since the non-hydrocarbon shocks originating from the GCC countries are unlikely to have a significant impact on the rest of the world economy, the foreign variables are treated as exogenous in our empirical model. ${ }^{20}$ We also allow for a contemporaneous impact of the exogenous variables on the endogenous GCC variables.

First, we consider a four-variable SVAR model of the joint dynamics of the following endogenous GCC variables: real non-hydrocarbon GDP $\left(y_{t}\right)$, consumer prices $\left(p_{t}\right)$, a broad measure of domestic credit $\left(m_{t}\right)$, and the domestic nominal short-term interest rate $\left(s_{t}\right)$ :

$$
Y_{t}^{\prime}=\left[\begin{array}{llll}
y_{t} & p_{t} & m_{t} & s_{t}
\end{array}\right]
$$

Since monetary developments have played an important role in the GCC countries, the inclusion of a monetary aggregate could be helpful in identifying the channels of monetary transmission. Second, in addition to the main policy variables, we examine the effect of the

\footnotetext{
${ }^{18}$ It is worth noting that the recursive modeling with the Cholesky decomposition assumes a triangular matrix, while the structural identification of the matrix assumes any structure as long as there are enough restrictions.

${ }^{19}$ By testing for weak exogeniety, we establish that these variables are weakly exogenous-i.e. $Y_{t}$ does not Granger cause $X_{t}$.

${ }^{20}$ The price is crude oil is included as an exogenous variable, assuming that international prices are formed according to market conditions and that the GCC countries do not attempt to influence the pricing process.
} 
real effective exchange rate $\left(x_{t}\right)$ in the block of endogenous variables. The SVAR isolates structural shocks by imposing restrictions on the long-run behavior of the variables in the model, and these long-run restrictions are derived directly from the underlying economic models. For all countries in the sample, we estimate the SVAR equations with only the CPI, as well as including both the CPI and the real effective exchange rate. The contemporaneous SVAR coefficients, reported in Table 3, include only the CPI, given that the pegged exchange rate regime inhibits the exchange rate channel. For only Bahrain, Qatar and the synthetic GCC aggregate, we report contemporaneous coefficients taken from the equation including the real effective exchange rate, which although not significant by itself contributes to the stability of the equation. In addition, while the spread between the GCC interest rates and the U.S. policy rate is not considered as a particular variable in the model, its behavior over time is reflected through the time series nature of the SVAR. Accordingly, the vector of endogenous variables in our model can be written as:

$$
Y_{t}^{\prime}=\left[\begin{array}{llll}
y_{t} & p_{t} & m_{t} & s_{t} \\
x_{t}
\end{array}\right]
$$

In both cases, a monetary shock is identified through a contemporaneous, recursive system in which innovations are assumed to be orthogonal and the variables ordered as in Equation [3] and Equation [4], as outlined by Sims (1980), Sims and Zha (1998) and Christiano, Eichenbaum, and Evans (1999). The structural representation of the VAR describes the effects of exogenous shocks by the means of impulse response analysis according to:

$$
\Omega Y_{t}=\Omega A(L) Y_{t-1}+B(L) X_{t}+e_{t}
$$

where the matrix $\Omega$ denotes the contemporaneous relationship between the variables and $\Omega e_{t}=u_{t}$, where $e_{t}$ denotes the vector of structural shocks, defined as a shock to a variable that is orthogonal to other shocks in the economy. Pre-multiplying with $\Omega^{-1}$ presents the relationship between the reduced form errors $u_{t}$ and the structural shocks $e_{t}$. For the purposes of our study, we denote the structural shocks $\left[e^{y} e^{p} e^{m} e^{s} e^{x}\right]^{\prime}$ and base our identifying restrictions on the above-mentioned economic models and particular economic reasoning.

$$
\begin{gathered}
{\left[\begin{array}{ccccc}
1 & 0 & 0 & 0 & 0 \\
\omega_{21} & 1 & 0 & 0 & 0 \\
\omega_{31} \omega_{32} & 1 & \omega_{34} & 0 \\
0 & 0 & 0 & 1 & 0 \\
0 & 0 & 0 & 0 & 1
\end{array}\right] \times Y_{t}=\left[\begin{array}{ccccc}
1 & 0 & 0 & 0 & 0 \\
\omega_{21} & 1 & 0 & 0 & 0 \\
\omega_{31} \omega_{32} & 1 & \omega_{34} & 0 \\
0 & 0 & 0 & 1 & 0 \\
0 & 0 & 0 & 0 & 1
\end{array}\right] A(L) Y_{t-1}+\left[\begin{array}{lllll}
1 & 0 & 0 & 0 & 0 \\
0 & 1 & 0 & 0 & 0 \\
0 & 0 & 1 & 0 & 0 \\
0 & 0 & 0 & 1 & 0 \\
0 & 0 & 0 & 0 & 1
\end{array}\right](L) X+\left[\begin{array}{c}
e^{y} \\
e^{p} \\
e^{m} \\
e^{s} \\
e^{x}
\end{array}\right]} \\
{\left[\begin{array}{l}
u^{y} \\
u^{p} \\
u^{m} \\
u^{s} \\
u^{x}
\end{array}\right]=\left[\begin{array}{ccccc}
1 & 0 & 0 & 0 & 0 \\
\omega_{21} & 1 & 0 & 0 & 0 \\
\omega_{31} \omega_{32} & 1 & \omega_{34} & 0 \\
0 & 0 & 0 & 1 & 0 \\
0 & 0 & 0 & 0 & 1
\end{array}\right]\left[\begin{array}{c}
e^{y} \\
e^{p} \\
e^{m} \\
e^{s} \\
e^{x}
\end{array}\right]}
\end{gathered}
$$


As expressed in Equation [6], non-hydrocarbon output $\left(y_{t}\right)$ and consumer prices $\left(p_{t}\right)$ respond to shocks to domestic credit $\left(m_{t}\right)$, short-term interest rates $\left(s_{t}\right)$, and the real effective exchange rate $\left(x_{t}\right) .{ }^{21}$ For example, in the case of a supply shock to output - the second equation in the above matrix, we allow consumer prices to respond contemporaneously. Similarly, the third equation can be interpreted as a short-run credit demand equation, with credit demand allowed to respond contemporaneously to shocks to output, consumer prices, and short-term interest. While the forth equation can be interpreted as the monetary policy reaction function, the last equation suggest that short-term interest rates and the exchange rate do not respond contemporaneously to other variables.

\section{B. Data Overview}

The SVAR model is estimated for the period of 1990-2010 using quarterly seasonallyadjusted data for the GCC countries. The dataset used in this paper is drawn from the IMF's International Financial Statistics and World Economic Outlook databases. We employ the three-month interest rate as an indicator of the monetary policy stance, since this is the only short-term interest rate series available for all countries over the sample period. ${ }^{22}$ The GCC countries do not publish quarterly national accounts, with the exception of Bahrain since 2008 and Qatar since 2005. Accordingly, lacking a quarterly proxy for nonhydrocarbon activity such as the industrial production index, we interpolate annual figures into quarterly frequency using an interpolation methodology. The interpolation is approximated using linear frequency conversion and assuming that real non-hydrocarbon GDP grows at a linear rate throughout the year (Chaw, 1993; Abeysinghe and Lee, 1998). ${ }^{23}$ The model also includes three exogenous variables - the price of crude oil, U.S. real GDP, and the U.S. nominal short-term interest rate - to avoid empirical anomalies, such as the price puzzle, and to correctly identify a monetary shock. All the variables are seasonally adjusted and expressed in logarithms, except for interest rates which are in first differences and not seasonally adjusted. In characterizing relationships between non-hydrocarbon output, the CPI, and policy variables, the stationary properties of the data are important. Therefore, we conduct a unit root test for stationarity of the variables using the Augmented Dickey Fuller (ADF) approach and the Phillips-Perron (PP) test, and the Akaike Information Criterion (AIC) to determine the optimal lag order. The results, presented in Table 1 and

\footnotetext{
${ }^{21} \omega_{21}$ is the impact of supply shock on consumer prices, $\omega_{31}$ is the impact of supply shock on bank lending, $\omega_{32}$ is the impact of demand shock on bank lending, and $\omega_{34}$ is the impact of interest rate shock on bank lending.

${ }^{22}$ Three-month market interest rates can theoretically be viewed as part of monetary transmission in developed markets, but we judge that credibility and expectations are less of an issue in the GCC countries and, lacking time-series data on the policy rate, short-term interest rates are the best proxy for the monetary policy variable.

${ }^{23}$ Given that interpolation may distort the results, we also utilize another interpolation method by fitting local quadratic polynomial. In addition, the stability of the coefficients is checked by applying the SVAR methodology to the interpolated annual GCC dataset, other than the synthetic aggregation.
} 
Table 2, suggest that the variables are integrated of order one in levels, and the optimal lag length is 4 for the SVAR model used in this paper. ${ }^{24}$

\section{We also construct "synthetic" macroeconomic and monetary series for the GCC as a} whole to develop a regional synopsis. Since the GCC, unlike the euro area, does not have region-wide macroeconomic and financial data, we construct a historical "synthetic" time series for the GCC as a whole to analyze the monetary transmission process from a regional perspective. Although these "synthetic" aggregate series do not represent an economic reality for the time being, they can still offer preliminary insights about the monetary transmission mechanism at an aggregated level, especially in view of the planned monetary union. Our aggregation methodology in this study is based on time-varying GDP weights - in light of the fact that the fixed-weight approach fails to reflect the changing economic and financial conditions - and therefore ensures a reasonable consistency between changes in the components of the GCC-wide aggregate and the behavior of the "synthetic" aggregate.

\section{Table 1. Unit Root Tests Results for GCC countries ${ }^{1 /, 2 /}$}

\begin{tabular}{|c|c|c|c|c|c|}
\hline Variables: & $\ln (\mathrm{RGDP})$ & $\ln (\mathrm{CPI})$ & $\ln (\mathrm{PRCRED})$ & $(\mathrm{IR})$ & $\ln (\mathrm{REER})$ \\
\hline \multicolumn{6}{|c|}{ Model with constant and trend in levels } \\
\hline ADF-test : & -1.85 & -2.58 & -1.74 & -1.46 & -1.01 \\
\hline PP-test : & -1.21 & -2.61 & -3.99 * & -1.55 & -1.13 \\
\hline \multicolumn{6}{|c|}{ Model with constant and trend in first differences } \\
\hline ADF-test & -2.42 & $-7.92 * *$ & $-13.11 * *$ & $-9.16 * *$ & $-9.51 * *$ \\
\hline PP-test : & $-9.00 * *$ & -7.92 ** & $-9.14 * *$ & $-9.16 * *$ & $-9.51 * *$ \\
\hline
\end{tabular}

Notes:

1/ Based on ADF and PP $t$-statistics for "synthetic" GCC.

2/ The null hypothesis is a unit root for both ADF and PP tests. The null hypothesis is that of a unit root in levels, i.e., rejection of the null means that the variable is stationary in levels. The symbols * and ${ }^{* *}$ denote significance at the 5 percent and 1 percent level, respectively.

Source: Authors' estimations.

\footnotetext{
${ }^{24}$ The unit root tests are based on specifications with a constant term included, though alternative specifications that include both a constant and a deterministic trend also produce similar results.
} 
Table 2. Specification tests of the GCC SVAR

\begin{tabular}{|c|c|c|c|c|}
\hline \multicolumn{5}{|c|}{ Panel A. Lag specification of the SVAR } \\
\hline Lag & AIC & SIC & $\log L^{1 /}$ & $\mathrm{LR}^{1 /}$ \\
\hline $\mathrm{k}=0$ & -2.93 & -2.04 & 108.54 & NA \\
\hline$k=1$ & -8.49 & $-6.698^{*}$ & 292.00 & 302.55 \\
\hline$k=2$ & -8.45 & -5.77 & 315.95 & 35.29 \\
\hline$k=3$ & -8.52 & -4.94 & 342.80 & 34.86 \\
\hline$k=4$ & $-9.88^{*}$ & -5.41 & 406.83 & $71.89^{*}$ \\
\hline \multicolumn{5}{|c|}{ Panel B. Misspecification tests for the SVAR } \\
\hline Series & $\mathrm{LM}_{-1}{ }^{3 /}$ & $\mathrm{LM}_{-4}{ }^{3 /}$ & Engle $\mathrm{LM}^{3 /}$ & $\times 2^{4 /}$ \\
\hline$\overline{\text { Bahrain }}$ & 26.06 & $17.16^{*}$ & 0.14 & 0.32 \\
\hline Kuwait & na & na & na & na \\
\hline Oman & na & na & na & na \\
\hline Qatar & 28.20 & 14.67 & 0.24 & na \\
\hline Saudi Arabia & 22.10 & 21.24 & 0.35 & $0.01^{*}$ \\
\hline U.A.E. & na & na & na & na \\
\hline "generic" GCC & $37.38^{*}$ & $51.57^{*}$ & 0.16 & na \\
\hline
\end{tabular}

Notes:

$1 /$ Log $L$ is the log-likelihood function; and LR-test is for lag order equal to $k$ against the alternative lag order equal to $\mathrm{k}+1$.

$2 / \mathrm{LM}$ is a Lagrange multiplier test for $\mathrm{j}$ order autocorrelation in the residuals.

$3 /$ Test is for first order autoregressive conditional heterocedasticity in the residuals, $p$-values

4/ X2 is the Doornik and Hansen test for normal residuals.

Source: Authors' calculations.

\section{ESTIMATION RESUlts}

This paper identifies the transmission of monetary shocks through various channels in individual GCC countries and for the "synthetic" GCC aggregate. ${ }^{25}$ In line with Bernanke and Blinder (1992) and Sims (1992), we investigate the importance of various monetary policy transmission channels, using a SVAR model, and obtain impulse response functions implied by the economic theory. This approach provides a meaningful insight into the linkages through which monetary policy decisions are transmitted to the real economy. Our main empirical findings, summarized in Table 3 and Table 4, suggest that:

- Output shocks have a long-lasting impact on consumer price inflation. Domestic prices react, on average, positively to supply shocks in Qatar, Saudi Arabia, and the "synthetic" GCC, while this transmission channel appears to be weaker in Bahrain, Kuwait, and

\footnotetext{
${ }^{25}$ We study the impact of $\omega_{21}$ (supply shock on prices) in addition to the monetary policy shocks ( $\omega_{32}$ is the impact of demand shock on bank credit, and $\omega_{34}$ is the impact of interest rate shock on bank credit).
} 
Oman. Although the initial responses in the case of Saudi Arabia and for the "synthetic" GCC aggregate are negative, the immediate effect of the shock dissipates and turns positive over time. We also find that consumer price inflation in the post-crisis period after 2008 has, to a large extent, been driven by exchange rate and unexpected inflation shocks. It is also worth noting that supply shocks explain 60 to 80 percent of the variation in non-hydrocarbon GDP.

- The impact of supply shock to bank credit is significant for all GCC countries. As shown by the coefficients of the SVAR model, bank lending to the private sector is vulnerable to supply shocks in all GCC countries. Saudi Arabia and the United Arab Emirates exhibit a greater degree of responsiveness relative to other Gulf countries. On the other hand, credit conditions in the GCC countries appear to be immune to demand shocks. None of the coefficients are significant likely owing to the central bank efforts to alleviate inflation pressures - domestic and imported - through the interest rate channel. The weak impact of demand shocks on credit to the private sector is also likely due to growing trade openness and the prevalence of administrated prices.

- The bank lending channel is significant for all GCC countries. The GCC central banks respond contemporaneously to innovations in the policy rates that constitute a reaction to foreign monetary shocks (e.g. changes in the U.S. Federal Reserve's monetary policy stance), pointing out the relative importance of the bank lending channel. According to our model, a monetary policy innovation has a significant effect on money markets in Qatar within one to three months, and is propagated through the money market to the real economy essentially by determining the marginal cost of credit funding. Similarly, monetary shocks have had effects in Bahrain and Oman, although the responses are not strongly identified.

- The exchange rate channel does not appear to be important for monetary policy transmission. The structural analysis provides evidence that the exchange rate does not play an important role in the transmission of monetary policy actions to the real economy in Bahrain, Qatar, or in the "synthetic" GCC aggregate. The lack of an exchange rate transmission channel can be explained by the pegged exchange rate regimes adopted in the GCC countries. Nevertheless, although nominal exchange rates are not allowed to fluctuate under a pegged regime, real exchange rates can vary and allow a limited scope for monetary policy to affect real variables through the exchange rate channel. 
Table 3. Estimated Contemporaneous SVAR Coefficients, 1990-2010

\begin{tabular}{|c|c|c|c|c|}
\hline Coefficient estimation & $\begin{array}{c}\text { Impact of supply } \\
\text { shock on prices } \\
(C 1)\end{array}$ & $\begin{array}{c}\text { Impact of supply } \\
\text { shock on credit } \\
(C 2) \\
\end{array}$ & $\begin{array}{c}\text { Impact of demand } \\
\text { shock on credit } \\
(\mathrm{C})\end{array}$ & $\begin{array}{l}\text { Impact of interest } \\
\text { rate shock on credit } \\
(C 4)\end{array}$ \\
\hline Bahrain & $0.16(1.27)$ & $2.36(18.74)^{*}$ & $0.03(0.28)$ & $-0.18(-1.34)$ \\
\hline Kuwait & $-0.63(-6.19)^{*}$ & $1.43(13.90)^{*}$ & $0.01(0.039)$ & $0.08(0.65)$ \\
\hline Oman & $-0.42(-4.16)^{*}$ & $1.25(12.11)^{*}$ & $0.13(1.21)$ & $-0.11(-1.04)$ \\
\hline Qatar & $3.31(16.59)^{*}$ & $1.41(6.96)^{*}$ & $0.16(0.80)$ & $-1.59(-7.98)^{*}$ \\
\hline Saudi Arabia & $5.55(45.49)^{*}$ & $2.78(22.75)^{*}$ & $-0.02(-0.06)$ & $0.15(1.25)$ \\
\hline United Arab Emirates & $-31.08(-135.48)^{*}$ & $4.28(18.47)^{*}$ & $-0.15(-0.64)$ & $0.23(1.01)$ \\
\hline GCC & $1.17(8.85)^{*}$ & $-0.26(-1.95)^{*}$ & $-0.01(-0.93)$ & $-0.01(-0.93)$ \\
\hline
\end{tabular}

Notes:

1/ Z-statistics in parenthesis is the so called "Fisher's z' transformation" that converts the sampling distribution to a normally distributed variable $z$ '. It is used for computing correlations confidence intervals and for confidence intervals on the difference between correlations.

2/ Statistically significant values are highlighted in bold.

3/ Bahrain, Qatar and the synthetic GCC contemporaneous coefficients are taken from a sample matrix including the real effective exchange rate.

Source: Authors' calculations.

\section{Analyzing the Robustness of the Results}

We examine different properties of the SVAR model presented in the paper to check the robustness of our empirical results. Using the Chow break point test as outlined by Weber, Gerke, and Worms (2010), we analyze the stability of parameters in the estimated individual SVAR equations by repeatedly searching for potential break points in the system. Our benchmark equations show significant stability at the aggregate level, although these results should be treated with caution. The $p$-values of test statistics do not reject the null hypothesis of stability, indicating that there is no structural break in the monetary transmission mechanism in individual GCC countries before 2008. However, although the null hypothesis of stability is not decisively rejected for the "synthetic" GCC aggregate, suggesting a structural break in the first and second quarters of 2008, this could be because of an aggregation problem.

\section{Impulse response functions help identify the impact of monetary policy shocks on} macroeconomic variables. To assess the overall dynamic impact of monetary policy shocks on real non-hydrocarbon GDP and consumer price inflation, we estimate impulse response functions within the 95 percent confidence intervals. For each country model, we report impulse responses of the key variables to a one standard deviation shock to policy variables in Appendix Figures 1-7, and the historical decomposition of forecast error variances in Appendix Figures 8-14. The confidence intervals are constructed around the estimated impulse response functions and the errors variance decompositions using the bootstrap technique explained above. Overall, the results suggest that the SVAR model presented in 
this paper estimates the impulse responses well, with narrow confidence bounds and in line with theoretical predictions.

- On average, positive supply shocks have the tendency to reduce prices in the GCC economies and increase bank lending temporarily, with this effect vanishing after one year.

- On the other hand, contractionary monetary policy shocks lead a decline in bank lending and consumer price inflation, with the effect dissipating much more quickly.

The variance decomposition analysis indicates the relative importance and impact of each structural innovation on the endogenous variables. As presented in Table 4, the results are summarized in terms of average percentage of variation attributed to each innovation over 10 quarters. Using the recursive Chow tests, we find that the benchmark SVARs are stable over the sample period. ${ }^{26}$ Evidence of the stability of impulse responses over time would suggest that the problems due to aggregation may be overrated. The recursive impulse responses also allow us to observe whether there is any evidence that the monetary transmission mechanism has changed over time.

- The variance of real non-hydrocarbon GDP attributable to the changes in monetary policy increased in the 2000s, accounting for 11 percent of output fluctuations.

- The variance of consumer price inflation due to the changes in monetary policy also increased over the past decade, giving an explanation for 15 percent of fluctuations.

These results conform to the theoretical expectation that the influence of monetary policy on prices under the fixed exchange rate regime is less powerful than with a flexible exchange rate. In addition, the monetary transmission mechanism works faster, although aggregation bias - stemming from the heterogeneity of inflation rates across the GCC countries - may distort the empirical results. Nevertheless, the SVAR approach identifies consistent and plausible relationships in the data, implying greater importance of the bank lending channel in monetary transmission across the GCC countries.

\footnotetext{
${ }^{26}$ Given that the $p$-values are significantly higher than 5 percent, the null hypothesis of stability - that is, the benchmark model has no structural break - cannot be rejected.
} 
Table 4. GCC: Variance Decomposition (percent of total variance)

Variance Decomposition of Output

\begin{tabular}{|c|c|c|c|c|c|c|}
\hline Period & Forecast Error & 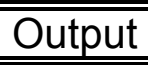 & Prices & Credit & Interest rate & Exchange rate \\
\hline 4 & 0.04 & 80.84 & 8.66 & 0.65 & 5.28 & 4.57 \\
\hline 6 & 0.06 & 73.28 & 8.02 & 1.27 & 3.75 & 13.68 \\
\hline 8 & 0.06 & 67.80 & 7.01 & 2.48 & 3.61 & 19.11 \\
\hline 10 & 0.07 & 67.53 & 6.85 & 2.66 & 3.31 & 19.65 \\
\hline \multicolumn{7}{|c|}{ Variance Decomposition of Prices } \\
\hline Period & Forecast Error & Output & Prices & Credit & Interest rate & Exchange rate \\
\hline 4 & 0.60 & 10.07 & 81.01 & 2.60 & 5.78 & 0.54 \\
\hline 6 & 0.63 & 9.94 & 74.49 & 2.68 & 11.62 & 1.26 \\
\hline 8 & 0.66 & 11.10 & 70.33 & 2.75 & 10.96 & 4.86 \\
\hline 10 & 0.67 & 11.79 & 68.04 & 3.56 & 11.28 & 5.33 \\
\hline \multicolumn{7}{|c|}{ Variance Decomposition of Credit } \\
\hline Period & Forecast Error & Output & Prices & Credit & Interest rate & Exchange rate \\
\hline 4 & 0.02 & 15.50 & 17.42 & 49.33 & 8.27 & 9.48 \\
\hline 6 & 0.04 & 36.98 & 11.67 & 33.52 & 5.17 & 12.65 \\
\hline 8 & 0.04 & 37.56 & 13.00 & 29.40 & 5.59 & 14.45 \\
\hline 10 & 0.04 & 34.48 & 17.15 & 29.28 & 5.26 & 13.82 \\
\hline \multicolumn{7}{|c|}{ Variance Decomposition of Interest rate } \\
\hline Period & Forecast Error & Output & Prices & Credit & Interest rate & Exchange rate \\
\hline 4 & 0.54 & 13.90 & 14.41 & 10.33 & 59.80 & 1.56 \\
\hline 6 & 0.57 & 13.96 & 14.07 & 9.42 & 61.10 & 1.45 \\
\hline 8 & 0.58 & 14.93 & 14.57 & 9.29 & 59.72 & 1.49 \\
\hline 10 & 0.59 & 15.45 & 14.28 & 9.40 & 59.25 & 1.61 \\
\hline \multicolumn{7}{|c|}{ Variance Decomposition of Exchange rate } \\
\hline Period & Forecast Error & Output & Prices & Credit & Interest rate & Exchange rate \\
\hline 4 & 0.04 & 13.03 & 4.00 & 7.33 & 2.40 & 73.23 \\
\hline 6 & 0.04 & 13.69 & 5.41 & 6.91 & 4.96 & 69.03 \\
\hline 8 & 0.04 & 17.04 & 6.88 & 7.88 & 5.09 & 63.12 \\
\hline 10 & 0.04 & 18.21 & 6.73 & 8.07 & 5.58 & 61.40 \\
\hline
\end{tabular}

Source: Authors' estimations. 


\section{Conclusion}

The interest rate and bank lending channels are relatively effective, while the exchange rate does not appear to be important. Using the SVAR framework, we identify the empirical patterns and relative importance of different channels in transmitting monetary policy shocks in individual GCC countries and for a "synthetic" region-wide aggregate. The results of our analysis indicate that the interest rate channel influences real non-hydrocarbon output and consumer price inflation in all GCC countries as well as for the "synthetic" GCC aggregate. In contrast, the exchange rate channel does not appear to have an important role as a mechanism of monetary policy transmission. This is not a surprising outcome, because these countries have long maintained pegged exchange rate regimes. While the empirical results also suggest that the bank lending channel has an important role in monetary policy transmission shocks, output shocks appear to play a most crucial role in promulgating monetary policy effects to non-hydrocarbon economic activity and prices through traditional transmission variables such as the long-term interest rate, bank lending, and the exchange rate.

One of the main constraints of monetary policy transmission is underdeveloped domestic financial markets. Banking sectors throughout the GCC have expanded significantly over the past decade, but domestic financial markets remain shallow and constrained by structural impediments. Measured by the ratio of broad money to GDP, for example, domestic money markets are illiquid and, on average, compare unfavorably with those of other emerging and developing countries. Similarly, collateralized interbank lending is not widely available, and secondary markets for government and central bank instruments are virtually non-existent. As a result, the underdeveloped state of the domestic financial markets has a bearing on not only interest rate and credit pass-through, but also all other channels of monetary policy transmission.

The GCC countries have ample scope to strengthen the effectiveness of monetary policy transmission mechanisms. Improved access to credit, as illustrated by the sustained increase in credit-to-GDP ratios over the past decade, appears to have contributed to the greater responsiveness of non-hydrocarbon output to changes in interest rates. Likewise, the larger role of bank credit in financing non-hydrocarbon economic activity implies a greater scope for bank lending effects. Nevertheless, there are still structural impediments, such as insufficient information on the credit quality of potential borrowers. The establishment of a regional network of credit bureaus could help alleviate the problem of asymmetric information that tends to lead to higher financing premiums and limits financial deepening. Furthermore, the financial infrastructure in the GCC countries remains dominated by the banking sector. Therefore, the development of domestic debt markets in the form of corporate and sovereign - conventional as well as Islamic - bond issuance could be highly successful in accelerating policy reforms. For example, the issuance of Sharia-compliant securities in local currency in recent years helped to sterilize surplus liquidity from the 
interbank money markets. In summary, greater monetary policy independence and structural reforms - aiming to deepen the domestic financial markets - would enhance the effectiveness of monetary policy transmission in the GCC countries.

\section{Increasing gains from monetary unification requires a higher degree of non-} hydrocarbon business cycle synchronization. The GCC has moved toward closer integration, aiming to form a monetary union, since its establishment in 1981 as a regional cooperation platform. An important criterion for participation in such a union - and the effectiveness of a common monetary policy - is business cycle synchronization. According to the theory of optimum currency area developed by Mundell (1961), the more synchronized the business cycles of the members of the currency union, the lower the probability of asymmetric shocks, and the less dramatic the loss of monetary and exchange rate policy for the member country. If business cycles in countries forming a currency union diverge considerably, the common monetary policy will not be optimal for all member countries. The empirical analysis, however, shows that the GCC countries have low and heterogeneous synchronization in non-hydrocarbon business cycles, as measured by the contemporaneous correlation coefficients of the cyclical components of each national non-hydrocarbon business cycle vis-à-vis others (Cevik, 2011). While the limited level of intra-regional trade and financial integration and variance in the degree of economic diversification contribute to business cycle desynchronization across the region, another important factor is the heterogeneous and diverging fiscal policies. These structural features present a series of challenges, particularly in light of the planned monetary integration, and require a set of common fiscal rules to align decentralized fiscal policies among the GCC countries. 


\section{Appendix Figure 1. GCC: Impulse Responses with Bootstrapped Confidence Intervals}
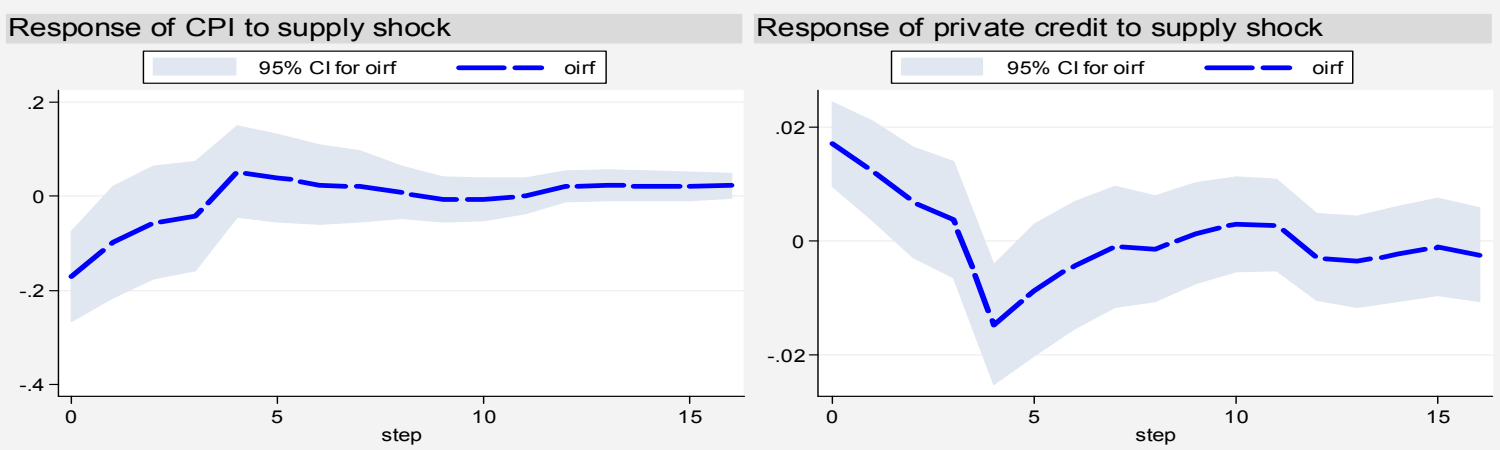

Response of private credit to inflation shock
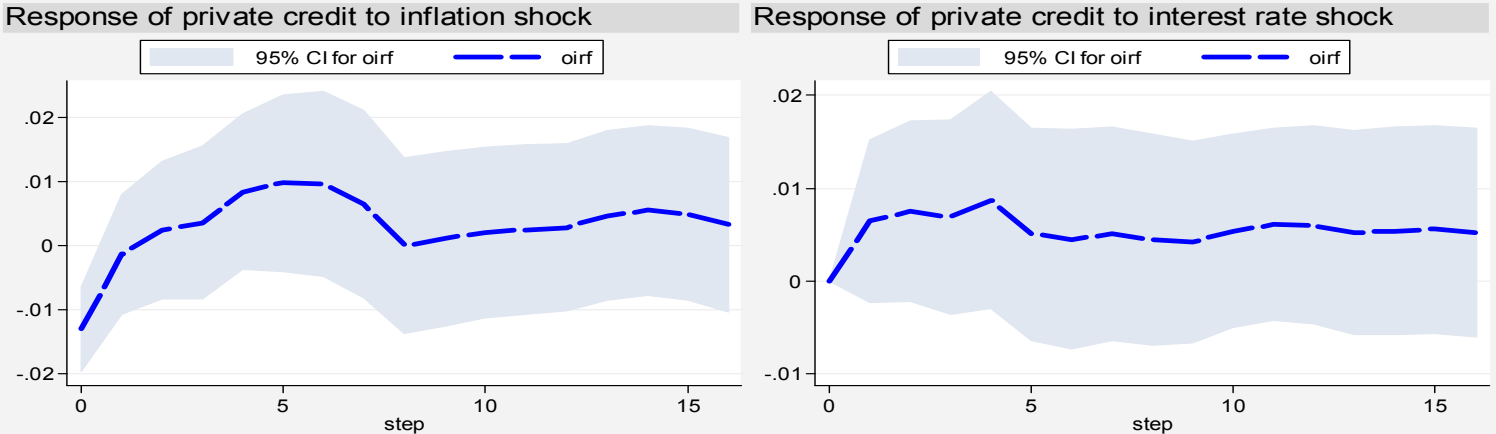

1/ A precise description of these confidence intervals can be found in Efron and Tibshirani (1993) and Hall (1992). In order to compute bootstrap confidence intervals, we have set the number of drawings to 1,000 .

Source: Authors' calculations

\section{Appendix Figure 2. Bahrain: Impulse Responses with Bootstrapped Confidence Intervals}
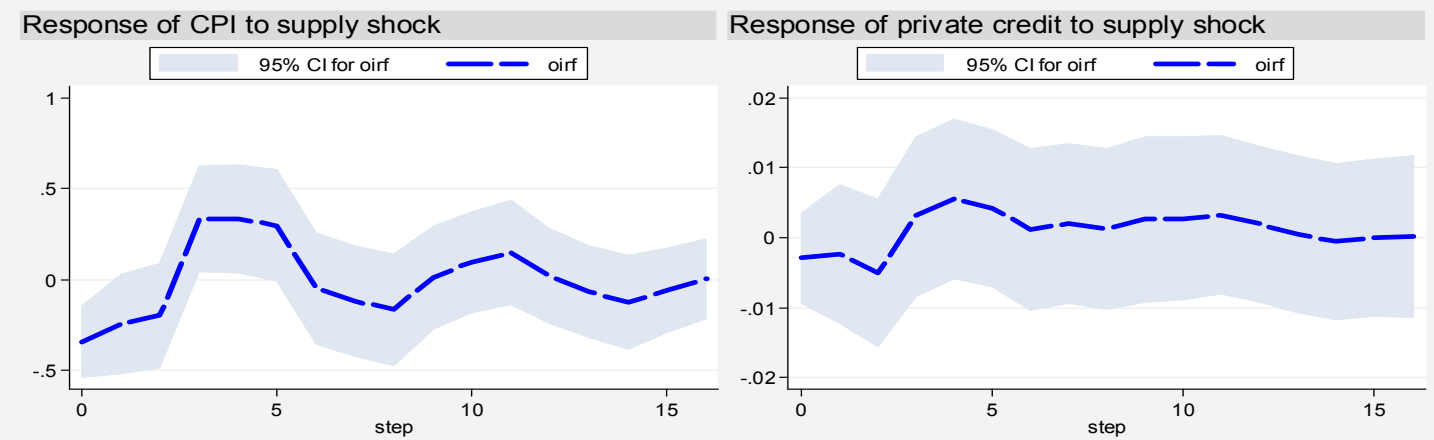

Response of private credit to inflation shock

Response of private credit to interest rate shock
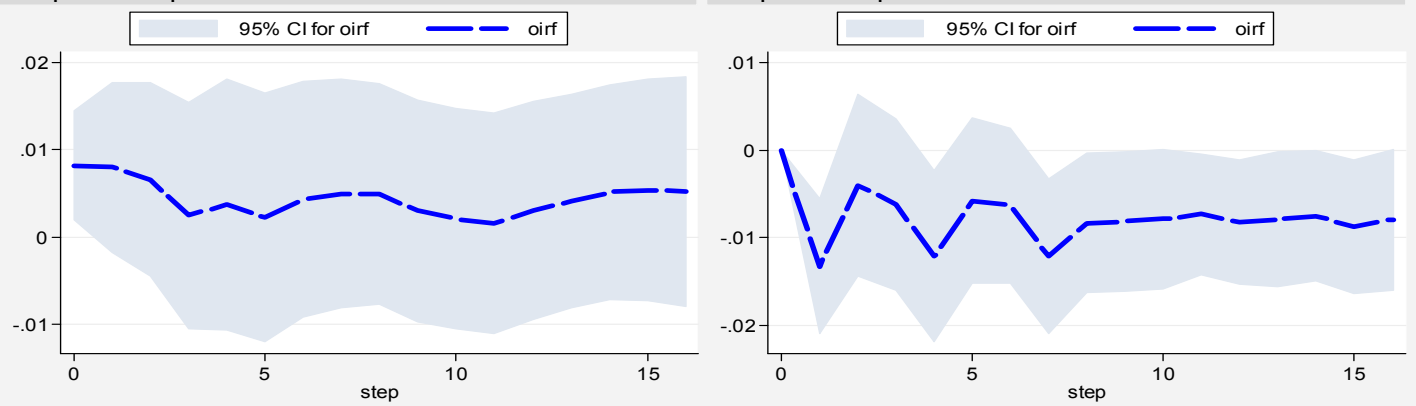

1/ A precise description of these confidence intervals can be found in Efron and Tibshirani (1993) and Hall (1992). In order to compute bootstrap confidence intervals, we have set the number of drawings to 1,000 . Source: Authors' calculations 


\section{Appendix Figure 3. Kuwait: Impulse Responses with Bootstrapped Confidence Intervals}
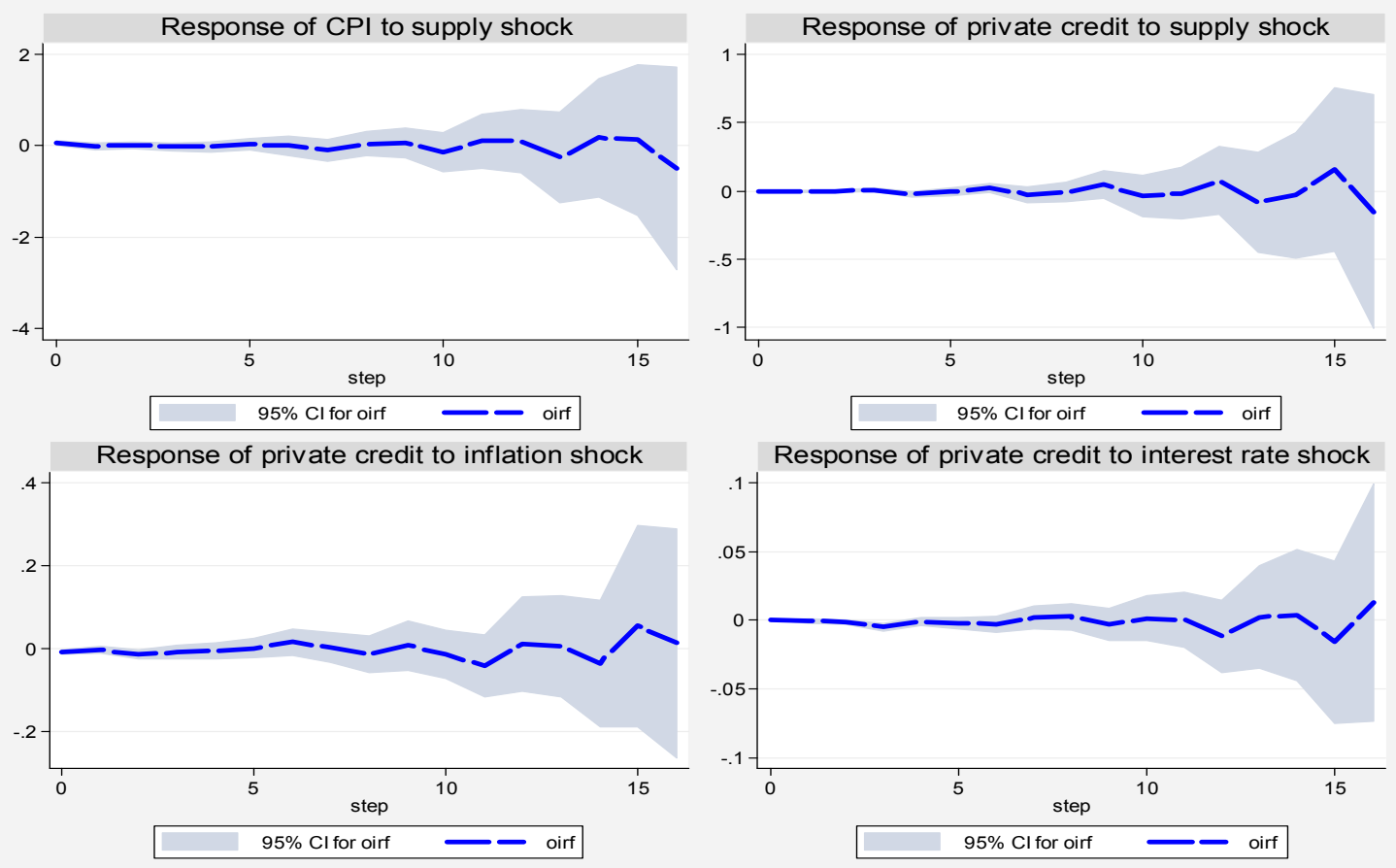

1/ A precise description of these confidence intervals can be found in Efron and Tibshirani (1993) and Hall (1992). In order to compute bootstrap confidence intervals, we have set the number of drawings to 1,000.

Source: Authors' calculations

\section{Appendix Figure 4. Oman: Impulse Responses with Bootstrapped Confidence Intervals}
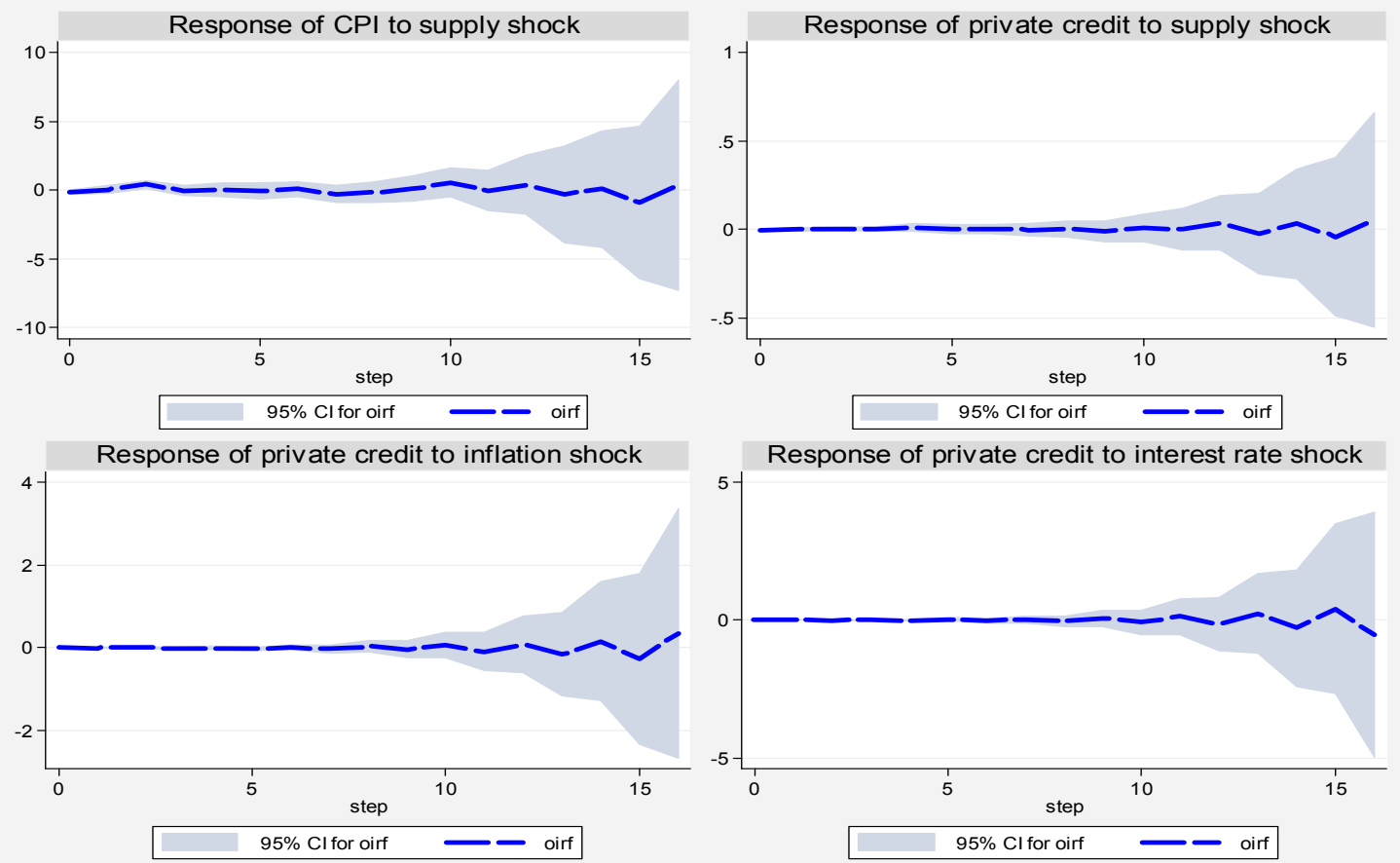

1/ A precise description of these confidence intervals can be found in Efron and Tibshirani (1993) and Hall (1992). In order to compute bootstrap confidence intervals, we have set the number of drawings to 1,000 .

Source: Authors' calculations 


\section{Appendix Figure 5. Qatar: Impulse Responses with Bootstrapped Confidence Intervals}
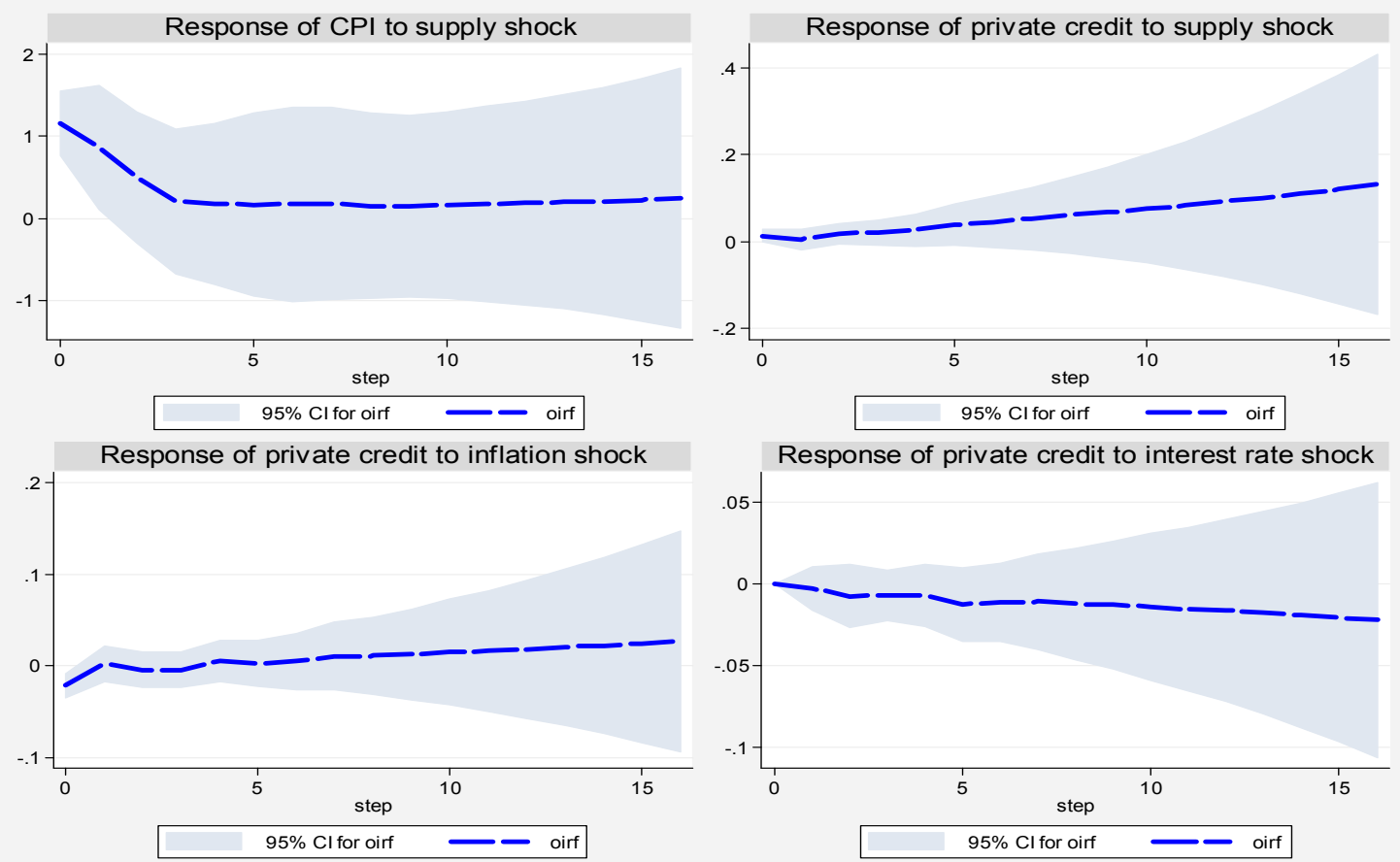

1/ A precise description of these confidence intervals can be found in Efron and Tibshirani (1993) and Hall (1992). In order to compute bootstrap confidence intervals, we have set the number of drawings to 1,000.

Source: Authors' calculations

\section{Appendix Figure 6. Saudi Arabia: Impulse Responses with Bootstrapped Confidence Intervals}
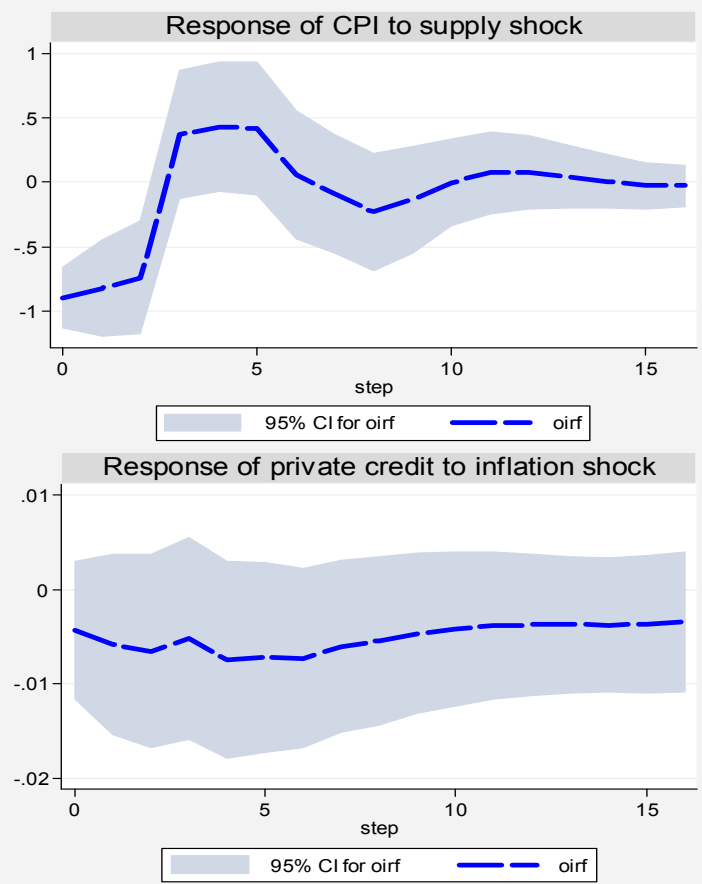

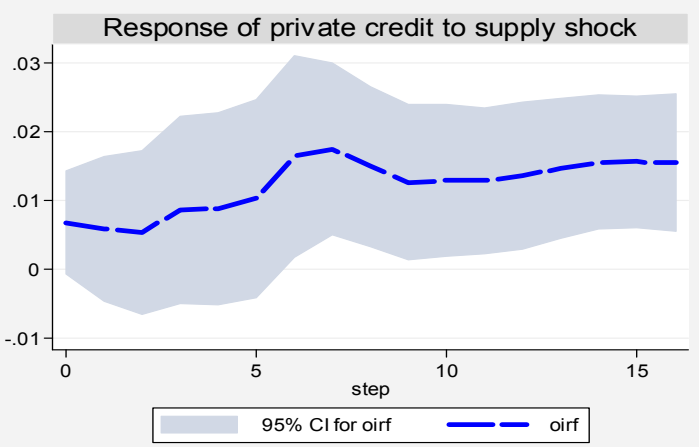

Response of private credit to interest rate shock

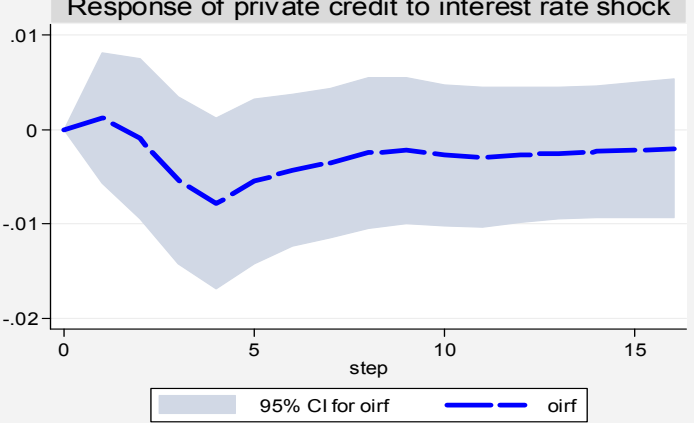

1/ A precise description of these confidence intervals can be found in Efron and Tibshirani (1993) and Hall (1992). In order to compute bootstrap confidence intervals, we have set the number of drawings to 1,000 . 


\section{Appendix Figure 7. U.A.E.: Impulse Responses with Bootstrapped Confidence Intervals}
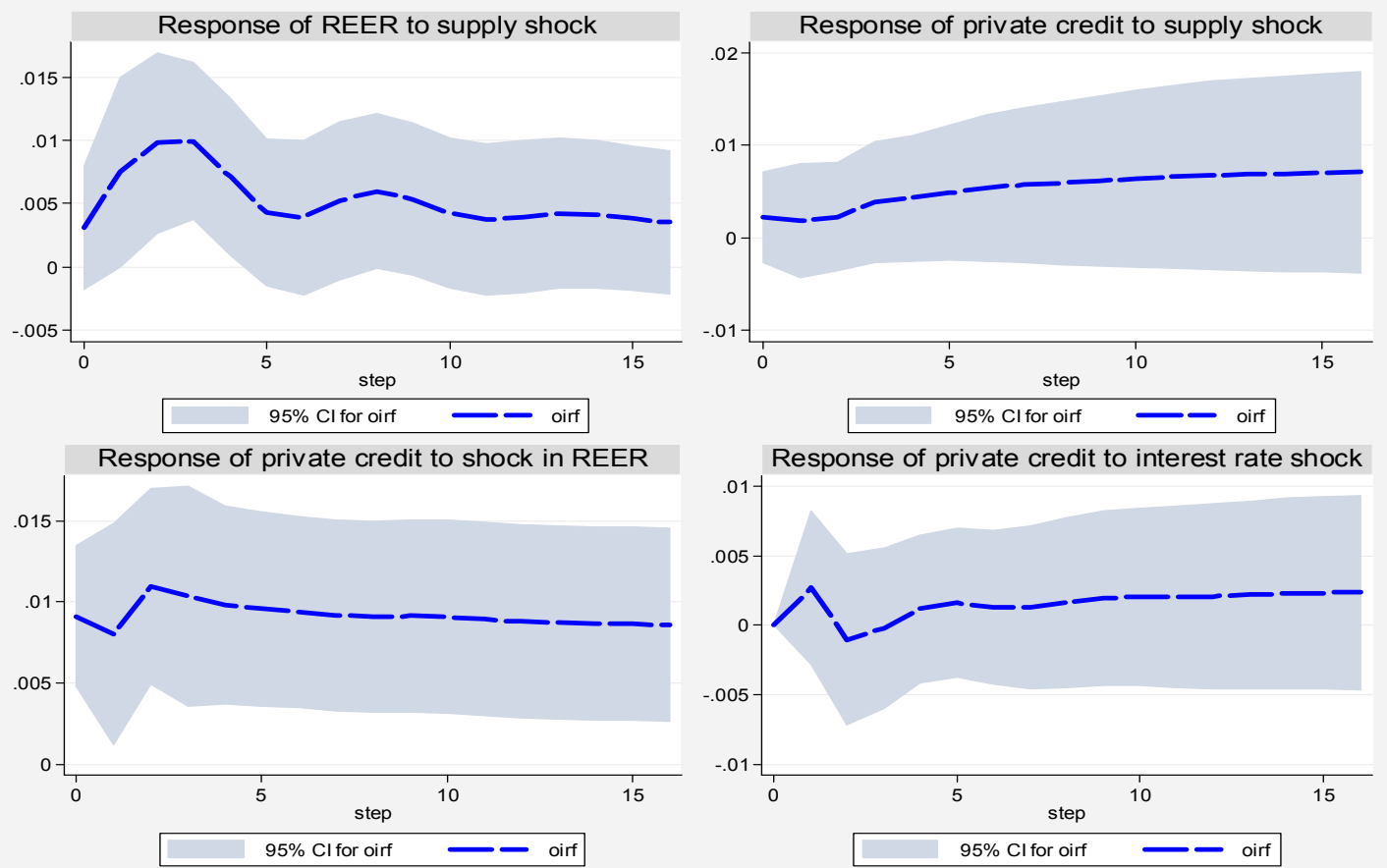

1/ A precise description of these confidence intervals can be found in Efron and Tibshirani (1993) and Hall (1992). In order to compute bootstrap confidence intervals, we have set the number of drawings to 1,000.

Source: Authors' calculations

\section{Appendix Figure 8. GCC: Variance Decomposition with Bootstrapped Confidence Intervals}

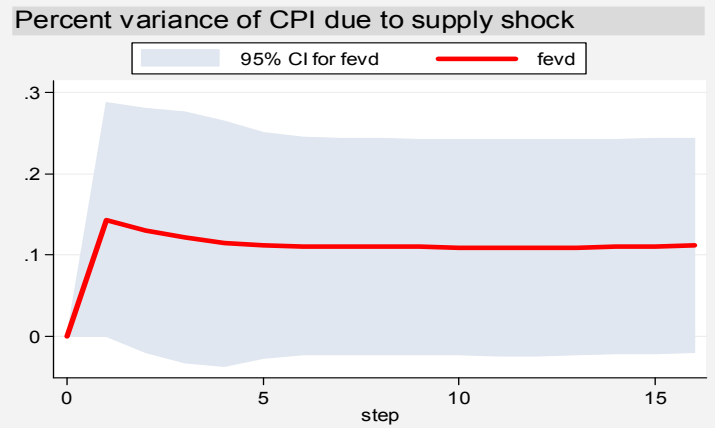

Percent variance of private credit due to supply shock
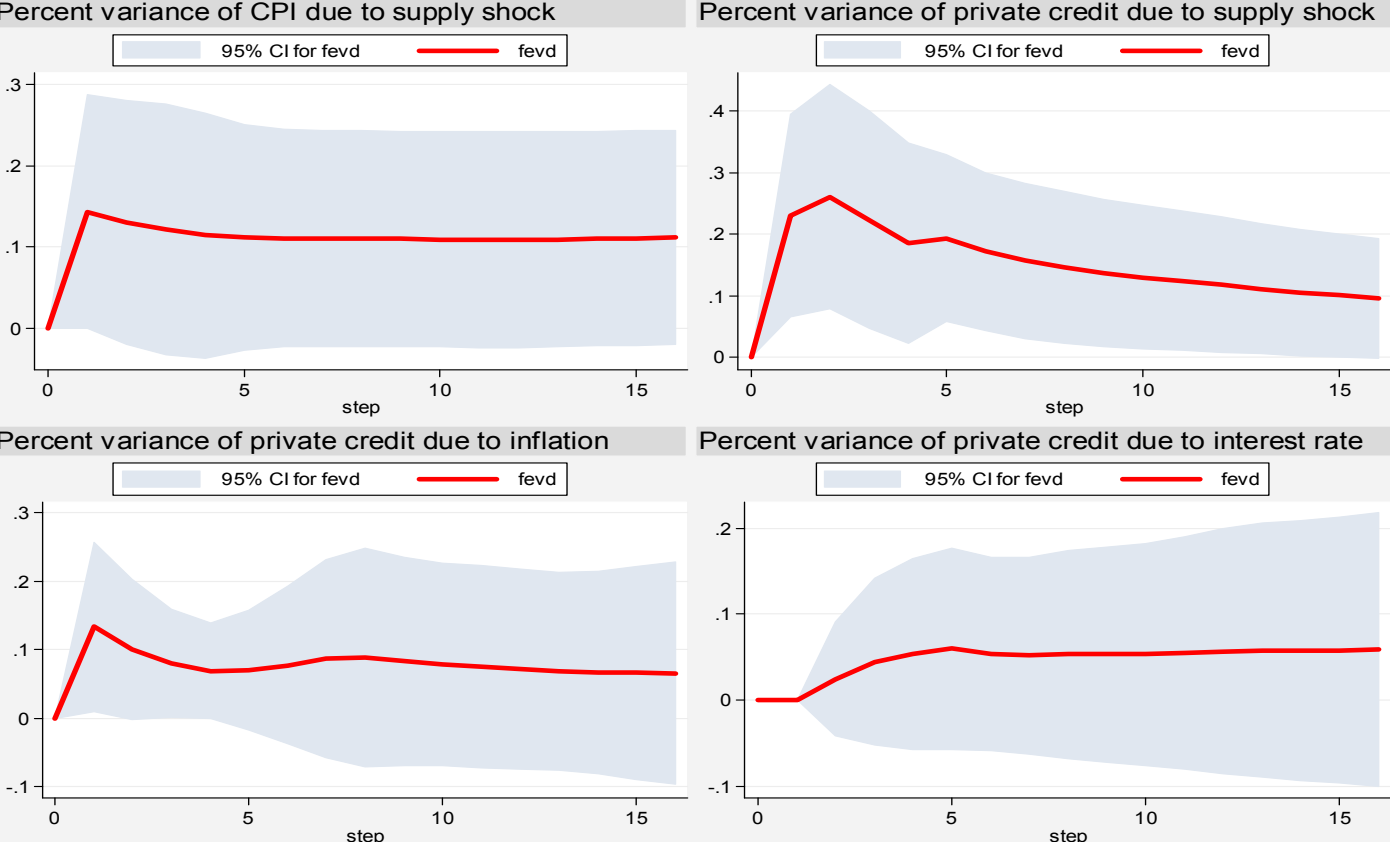

Percent variance of private credit due to interest rate

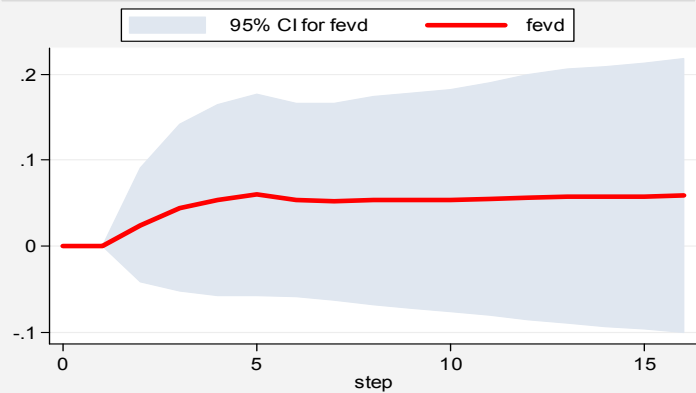

1/ A precise description of these confidence intervals can be found in Efron and Tibshirani (1993) and Hall (1992). In order to compute bootstrap confidence intervals, we have set the number of drawings to 1,000.

Source: Authors' calculations 


\section{Appendix Figure 9. Bahrain: Variance Decomposition with Bootstrapped Confidence Intervals}
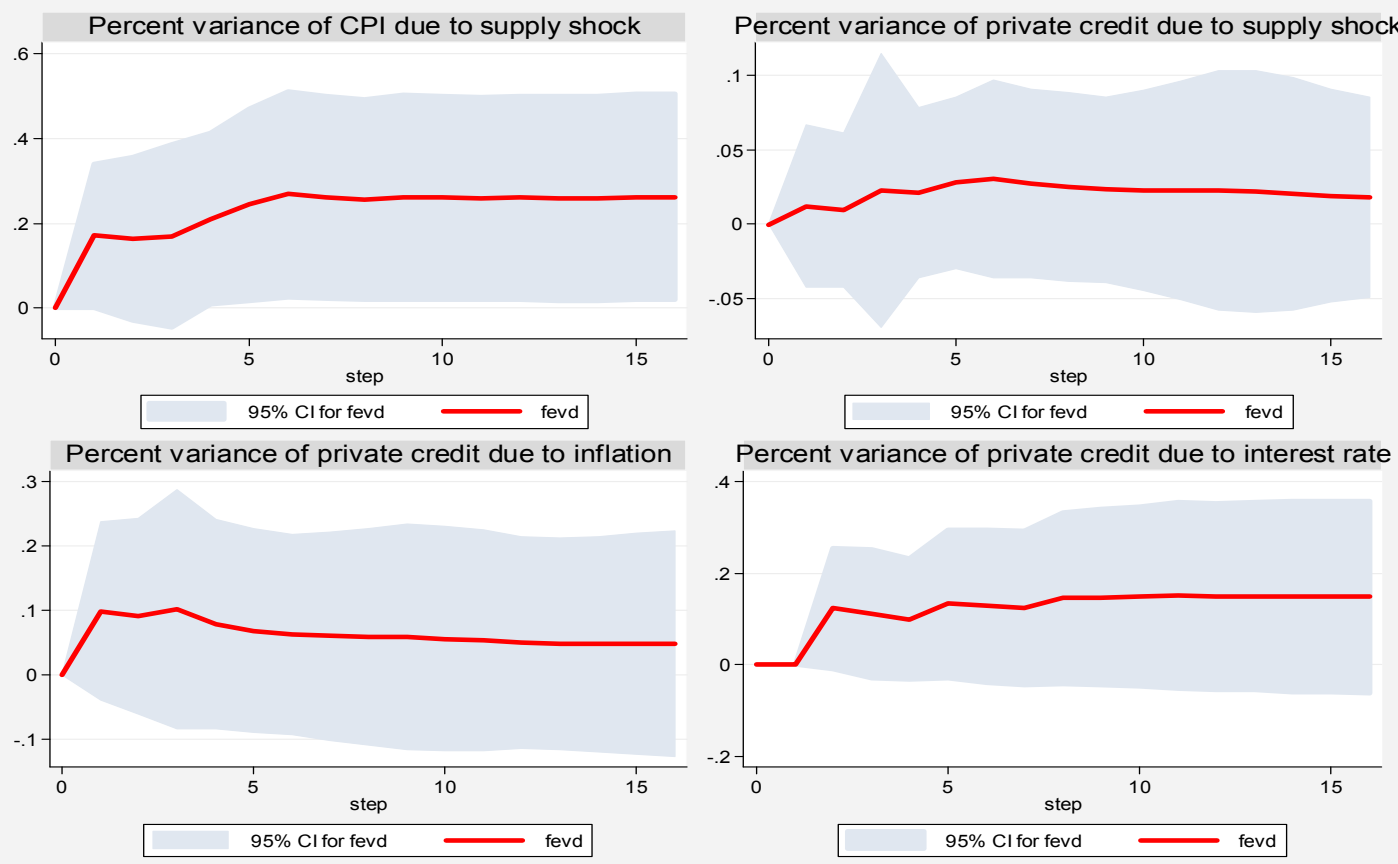

1/ A precise description of these confidence intervals can be found in Efron and Tibshirani (1993) and Hall (1992). In order to compute bootstrap confidence intervals, we have set the number of drawings to 1,000 .

Source: Authors' calculations

\section{Appendix Figure 10. Kuwait: Variance Decomposition with Bootstrapped Confidence Intervals}
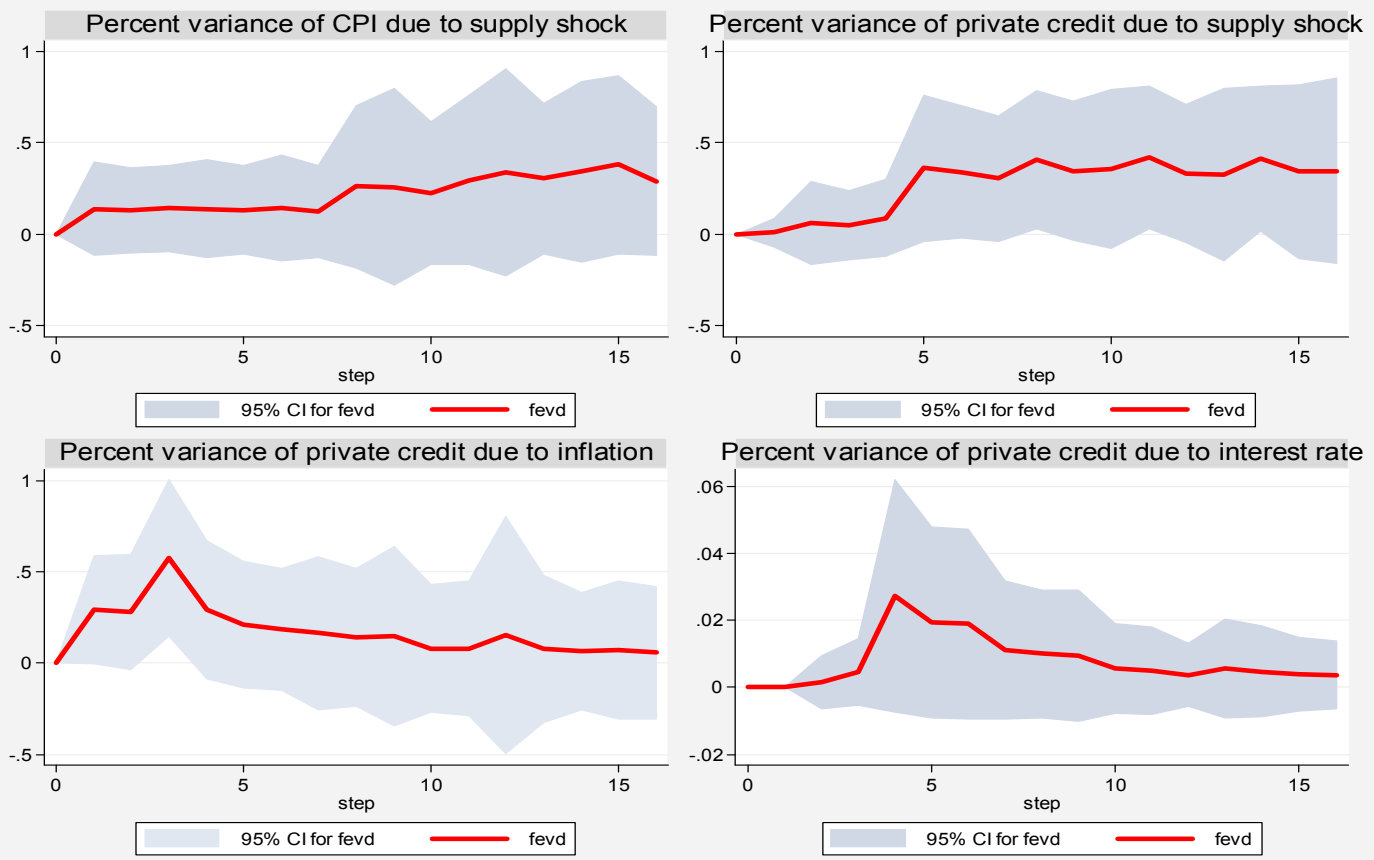

1/ A precise description of these confidence intervals can be found in Efron and Tibshirani (1993) and Hall (1992). In order to compute bootstrap confidence intervals, we have set the number of drawings to 1,000 .

Source: Authors' calculations 


\section{Appendix Figure 11. Oman: Variance Decomposition with Bootstrapped Confidence Intervals}
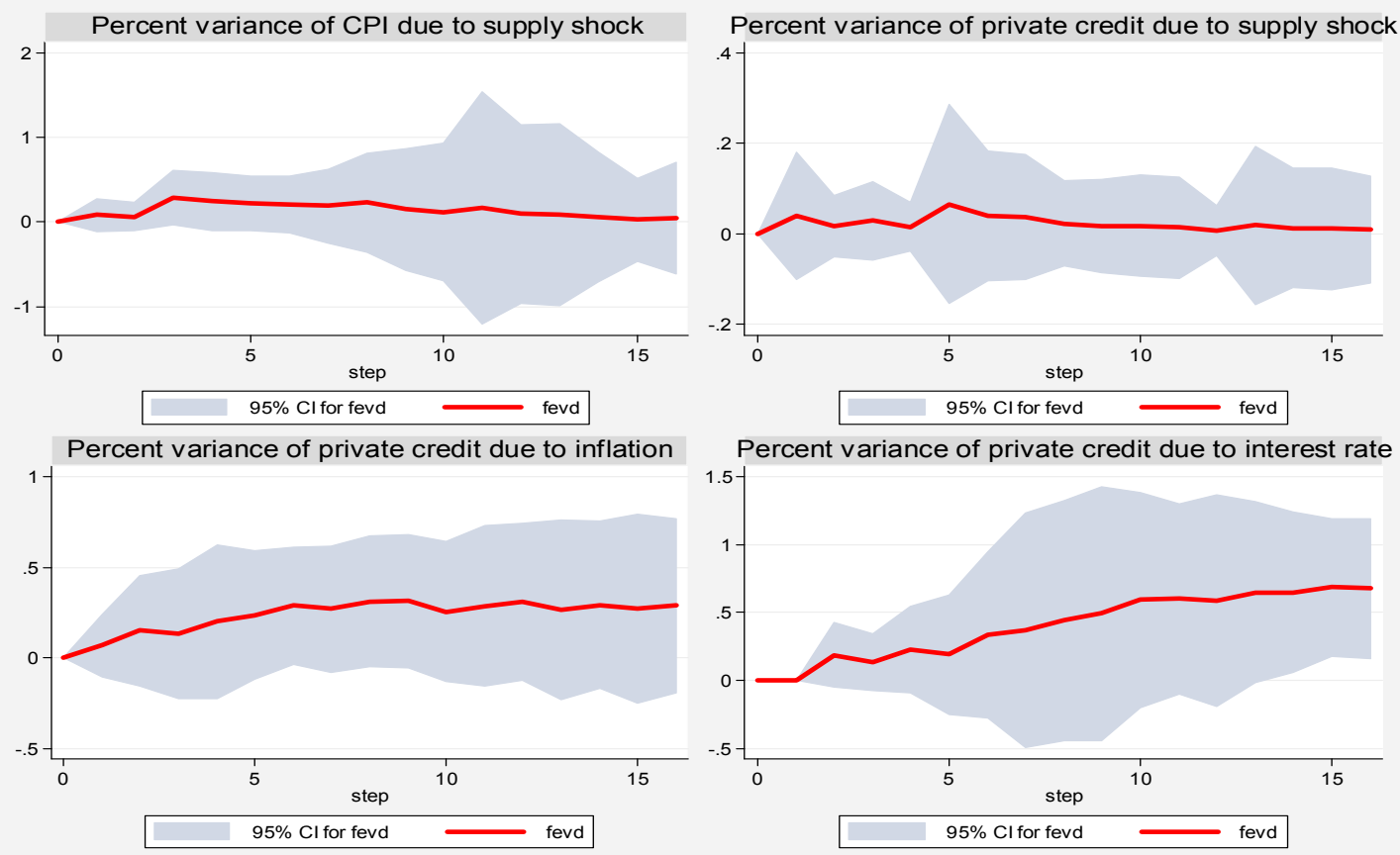

1/ A precise description of these confidence intervals can be found in Efron and Tibshirani (1993) and Hall (1992). In order to compute bootstrap confidence intervals, we have set the number of drawings to 1,000 .

Source: Authors' calculations

\section{Appendix Figure 12. Qatar: Variance Decomposition with Bootstrapped Confidence Intervals}
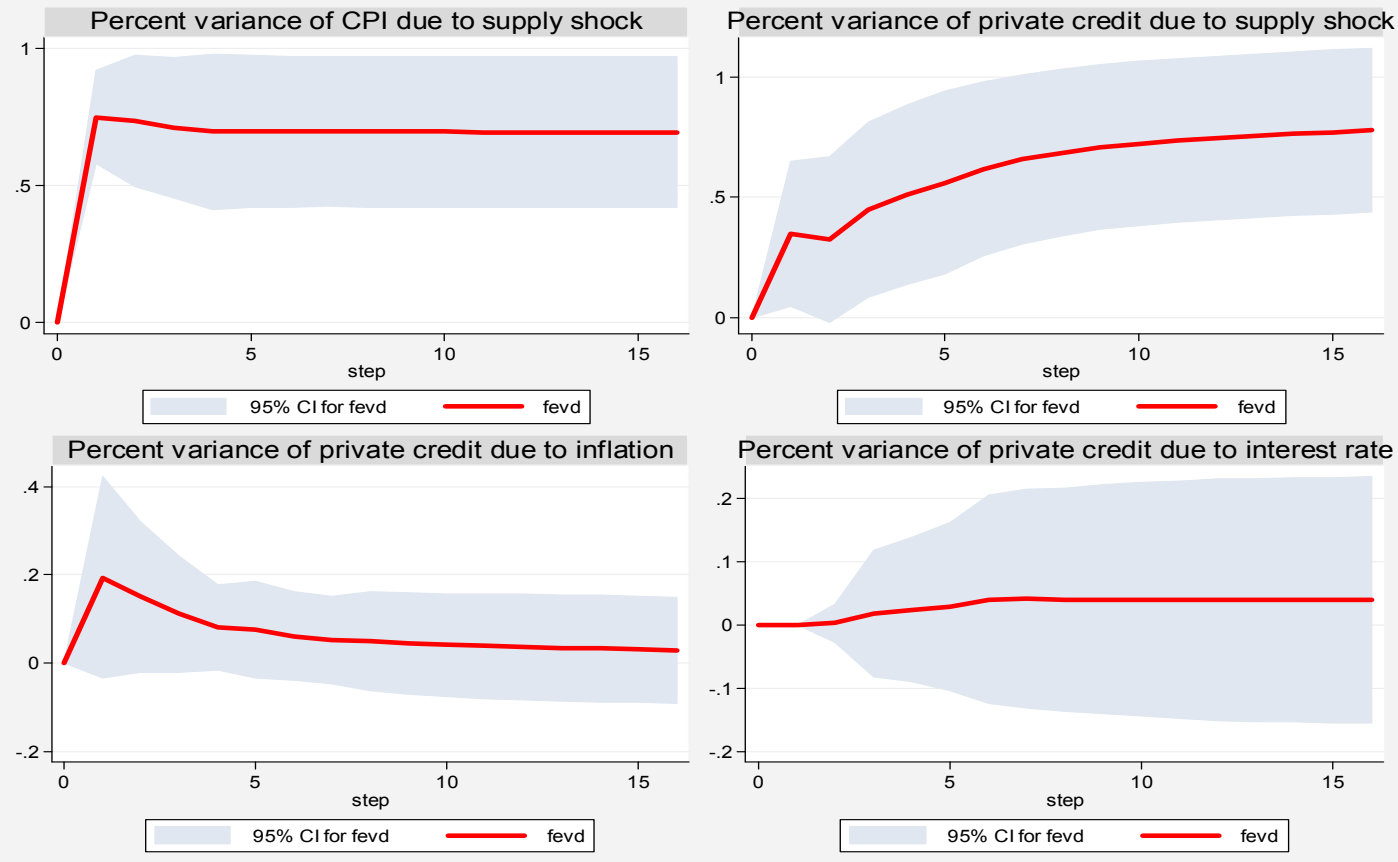

1/ A precise description of these confidence intervals can be found in Efron and Tibshirani (1993) and Hall (1992). In order to compute bootstrap confidence intervals, we have set the number of drawings to 1,000 .

Source: Authors' calculations 


\section{Appendix Figure 13. Saudi Arabia: Variance Decomposition with Bootstrapped Confidence Intervals}
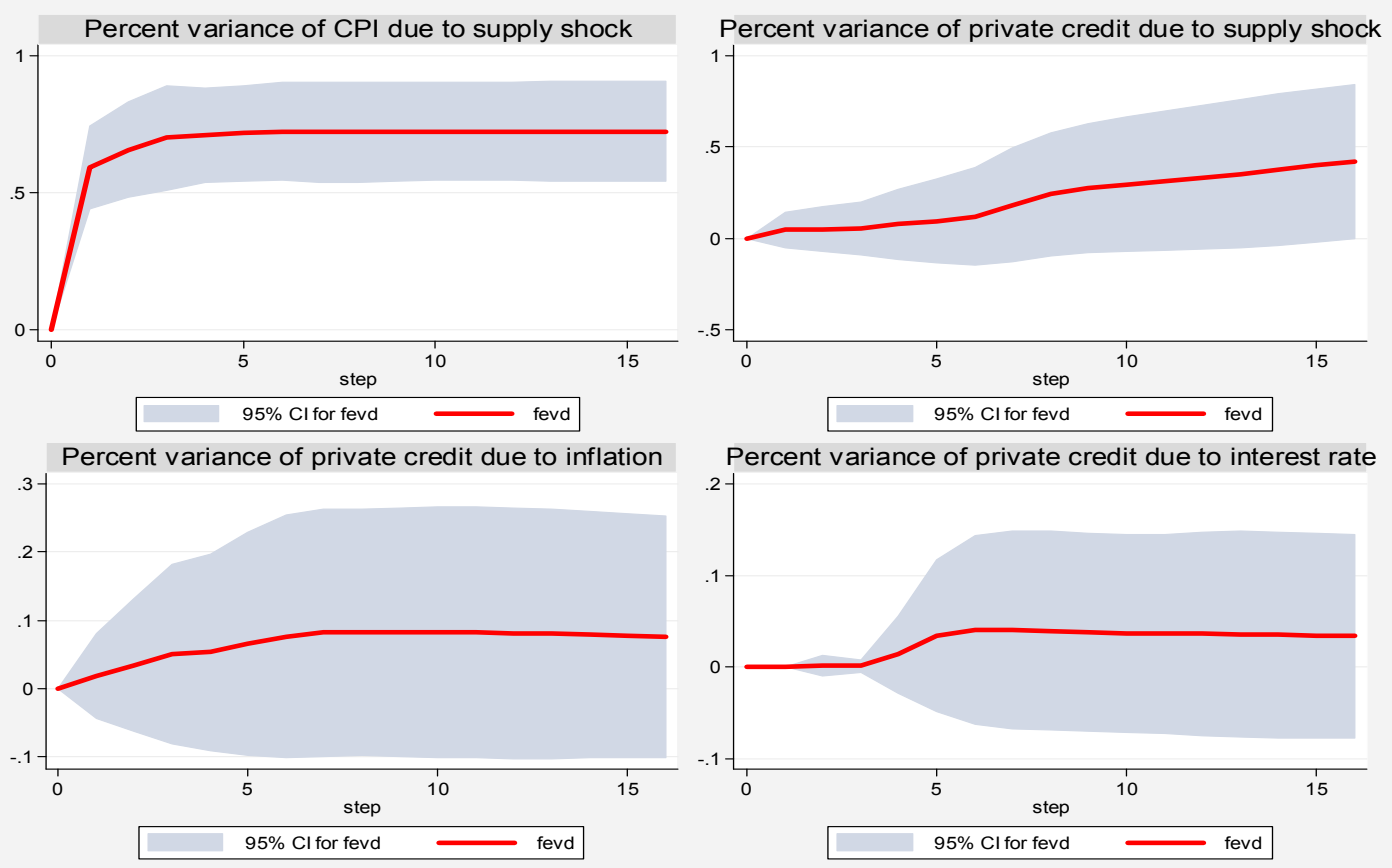

1/ A precise description of these confidence intervals can be found in Efron and Tibshirani (1993) and Hall (1992). In order to compute bootstrap confidence intervals, we have set the number of drawings to 1,000 .

Source: Authors' calculations

\section{Appendix Figure 14. U.A.E.: Variance Decomposition with Bootstrapped Confidence Intervals}
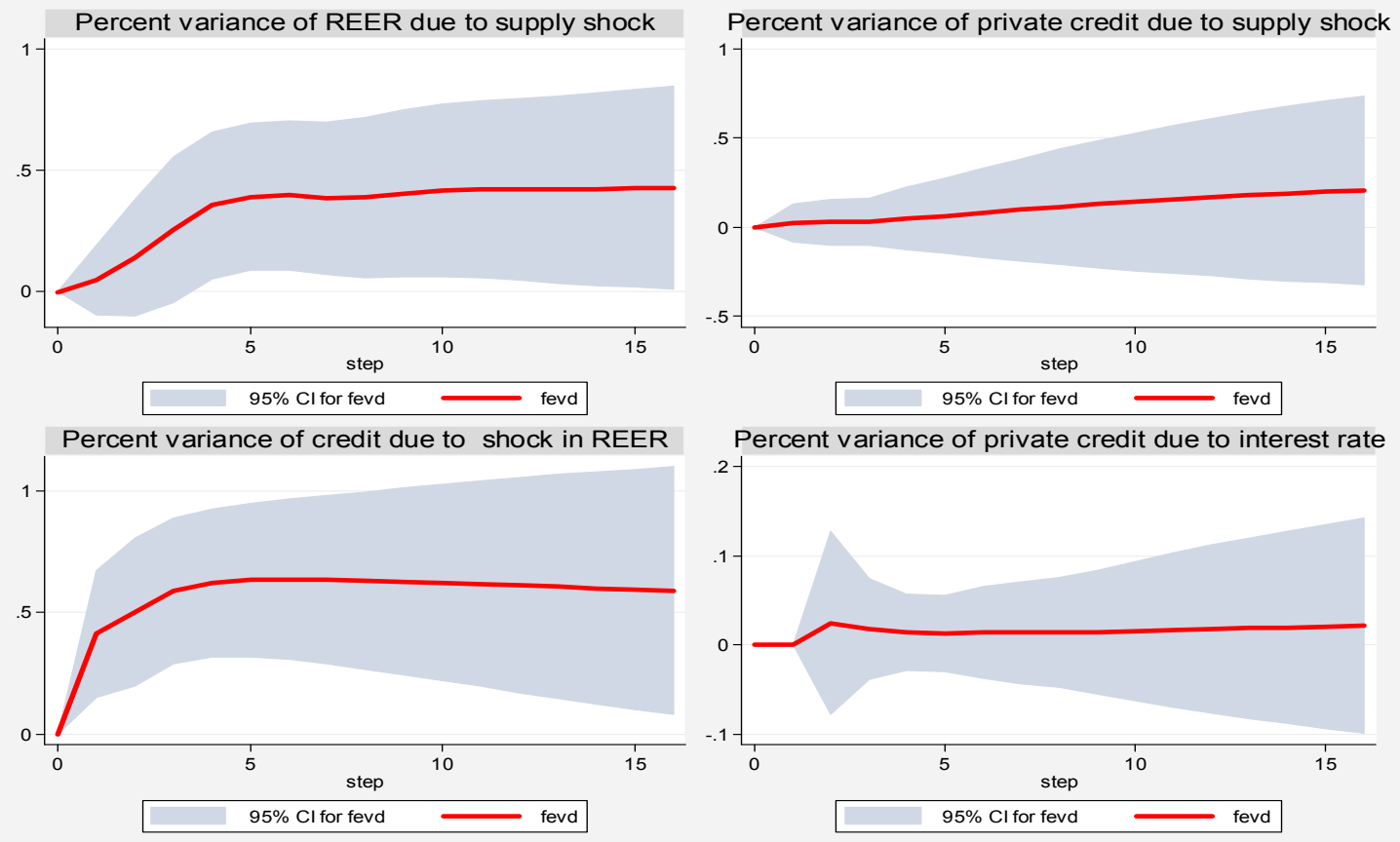

1/ A precise description of these confidence intervals can be found in Efron and Tibshirani (1993) and Hall (1992). In order to compute bootstrap confidence intervals, we have set the number of drawings to 1,000 .

Source: Authors' calculations 


\section{REFERENCES}

Abeysinghe, T. and C. Lee, 1998. "Best Linear Unbiased Disaggregation of Annual GDP to Quarterly Figures: The Case of Malaysia," Journal of Forecasting, Vol. 17, pp. 527-537.

Altunbas, Y., L. Gambacorta, and D. Marqués-Ibáñez, 2010. "Does Monetary Policy Affect Bank Risk-Taking?,” European Central Bank Working Paper, No. 1166 (Frankfurt: European Central Bank).

Bernanke, B., and A. Blinder, 1988, "Credit, Money, and Aggregate Demand," American Economic Review, Vol. 78, pp. 435-439.

Bernanke, B., and A. Blinder, 1992, "The Federal Funds Rate and the Channels of Monetary Transmission," American Economic Review, Vol. 82, pp. 901-921.

Bernanke, B., and M. Gertler, 1995, "Inside the Black Box: The Credit Channel of Monetary Transmission," Journal of Economic Perspectives, Vol. 9, pp. 27-48.

Bernanke, B., and I. Mihov, 1998, "Measuring Monetary Policy,” NBER Working Paper, No. 5145 (Cambridge, MA: National Bureau for Economic Research).

Blanchard, O., 1990, "Why Does Money Affect Output? A Survey" in Handbook of Monetary Economics II, edited by B. Friedman and F. Hahn (New York: Elsevier).

Blanchard, O., and D. Quah, 1989, “The Dynamic Effects of Aggregate Demand and Supply Disturbances," American Economic Review, Vol. 79, pp. 655-673.

Boivin, J., M. Kiley and F. Mishkin, 2010, "How Has the Monetary Transmission Mechanism Evolved over Time," NBER Working Paper, No. 15879 (Cambridge, MA: National Bureau for Economic Research).

Chan, W., 1993, "Disaggregation of Annual Time-Series Data to Quarterly Figures: A Comparative Study,” Journal of Forecasting, Vol. 12, pp. 677-688.

Cevik, S., 2011, "Desynchronized: The Comovement of Non-Hydrocarbon Business Cycles in the GCC," IMF Working Paper, No. 11/286 (Washington: International Monetary Fund).

Christiano, L., M. Eichenbaum, and Evans, 1999, "Monetary Policy Shocks: What Have We Learned and to What End?," in Handbook of Macroeconomics, edited by B. Taylor and M. Woodford, pp. 651-748 (New York: Elsevier).

Clarida, R. and J. Gali, 1994, "Sources of Exchange Rate Fluctuations: How Important are Nominal Shocks?” Carnegie-Rochester Conference on Public Policy, Vol. 41, pp. 1-56. 
Efron, B. and R. Tibshirani, 1993, An Introduction to the Bootstrap (New York: Chapman \& Hall).

Espinoza, R., and A. Prasad, 2012, "Monetary Policy Transmission in the GCC Countries," IMF Working Paper, No. 12/132 (Washington: International Monetary Fund).

Hall, P., 1992, The Bootstrap and Edgeworth Expansion (New York: Springer-Verlag).

Kilian, L., 1998, "Small Sample Confidence Intervals for Impulse Response Functions," The Review of Economics and Statistics, Vol. 80, pp. 218-230.

Mishkin, F., 1996, "The Channels of Monetary Transmission: Lessons for Monetary Policy," NBER Working Paper, No. 5464 (Cambridge, MA: National Bureau for Economic Research).

Mundell, R., 1961, “A Theory of Optimum Currency Areas,” American Economic Review, Vol. 51, pp. 657-665.

Olivero, M., Y. Li, and B. Jeon, 2011, "Competition in Banking and the Lending Channel: Evidence from Bank-Level Data in Asia and Latin America," Journal of Banking and Finance, Vol. 35, pp. 560-571.

Prasad, A., and M. Khamis, 2011, "Monetary Policy and the Transmission Mechanism in the GCC Countries," in Gulf Cooperation Council Countries: Enhancing Economic Outcomes in an Uncertain Global Economy, edited by S. Beidas-Strom, T. Rasmussen, and D. Robinson (Washington: International Monetary Fund).

Sims, C., 1980, “Macroeconomics and Reality,” Econometrica, Vol. 48, pp. 1-48.

Sims, C., 1992, "Interpreting the Macroeconomic Time Series Facts: The Effects of Monetary Policy," European Economic Review, Vol. 36, pp. 975-1011.

Sims, C., and T. Zha, 1998, "Bayesian Methods for Dynamic Multivariate Models," International Economic Review, Vol. 39, pp. 949-968.

Sims, C., and T. Zha, 1999, "Error Bands for Impulse Responses,” Econometrica, Vol. 67, pp. 1113-1155.

Sims, C., 2012, "Statistical Modeling of Monetary Policy and Its Effects," American Economic Review, Vol. 102, pp. 1187-1205. 
Taylor, J., 1995, "The Monetary Transmission Mechanism: An Empirical Framework," Journal of Economic Perspectives, Vol. 9, pp. 11-26.

Weber, A., R. Gerke, and A. Worms, 2010, "Changes in euro area monetary transmission?," Applied Financial Economics, Vol. 21, pp. 131-145.

Ziaei, S. M., 2009, "Assess the Long-Run Effects of Monetary Policy on Bank Lending, Foreign Asset and Liability in MENA Countries," MPRA Working Paper, No. 14331, University Library of Munich, Germany. 